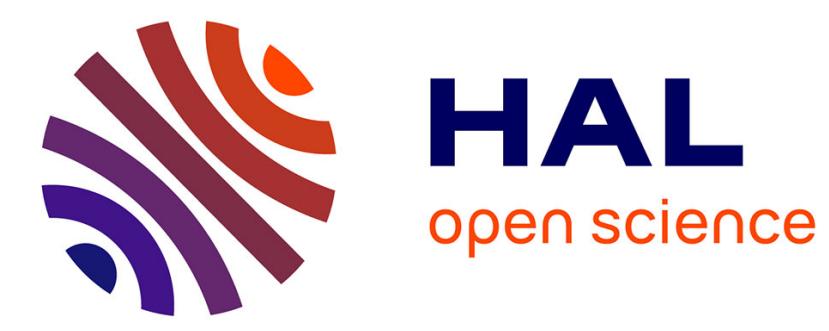

\title{
Gender, information and the efficiency of household production decisions: An experiment in rural Togo
}

Marie Christine Apedo-Amah, Habiba Djebbari, Roberta Ziparo

\section{To cite this version:}

Marie Christine Apedo-Amah, Habiba Djebbari, Roberta Ziparo. Gender, information and the efficiency of household production decisions: An experiment in rural Togo. 2019. halshs-02462673v2

\section{HAL Id: halshs-02462673 \\ https://shs.hal.science/halshs-02462673v2}

Preprint submitted on 18 Mar 2020

HAL is a multi-disciplinary open access archive for the deposit and dissemination of scientific research documents, whether they are published or not. The documents may come from teaching and research institutions in France or abroad, or from public or private research centers.
L'archive ouverte pluridisciplinaire HAL, est destinée au dépôt et à la diffusion de documents scientifiques de niveau recherche, publiés ou non, émanant des établissements d'enseignement et de recherche français ou étrangers, des laboratoires publics ou privés. 


\section{amse}

école d'économie d'aix-marseille

aix-marseille school of economics

\section{Working Papers / Documents de travail}

\section{Gender, information and the efficiency of household production decisions: An experiment in rural Togo}

Marie Christine Apedo-Amah Habiba Djebbari

Roberta Ziparo 


\title{
GENDER, INFORMATION AND THE EFFICIENCY OF HOUSEHOLD PRODUCTION DECISIONS: An EXPERIMENT IN RURAL TOGO
}

\author{
Marie Christine APEDO-AMAH† Habiba DJEBBARI‡ Roberta ZIPARO ${ }^{\S}$
}

This version: September 17, 2019

\begin{abstract}
Why do farm households inefficiently allocate resources across the plots they cultivate? We explore how these production inefficiencies relate to consumption decisions and information sharing within the household. In a lab-in-the-field experiment, male producers allocate too few inputs to their wife's plot, failing to maximize household aggregate profits. They do transfer more inputs when the returns from that plot are higher. Experimental manipulation of information on these returns triggers heterogenous responses across households. We provide a theoretical framework that rationalizes these findings and further leads to sharp predictions. Joint contribution to a household public good compels spouses to make efficient production decisions. Only households who are in a separate-sphere regime experience inefficiency in farm production and are unable to effectively communicate on returns to avoid extra losses. Consistent with this framework, when we experimentally offer an ex post information verification mechanism, additional losses due to information asymmetries are prevented. JEL Codes: Q12, C72, D13, D82, C91, C93.

KEYWORDS: farm households, household production and intra-household allocation, non-cooperative game theory, asymmetric and private information, lab-in-the-field experiment.
\end{abstract}

\footnotetext{
*We thank Cheryl Doss, Marcel Fafchamps, Patrick Francois, Garance Genicot, Martin Ravaillon, Christine Valente, Tanguy Van Ypersele, Alessandra Voena and participants to SEEDEC 2018, CSAE 2018, GRETha Internaitonal Conference on Economic Development 2018, African Region Econometric Society 2018 and Bordeaux Applied Economics Workshop Family and Development for helpful comments. We thank Herve Akinocho and his team at the Center for Research and Opinion Pools for excellency in the field implementation of the study, and Aharh-Kpessou and Lanwi Paka and their team at the National Cotton Society of Togo for facilitating field work. This work was supported by French National Research Agency grant ANR-17-EURE-0020. Corresponding author: Habiba Djebbari, Aix Marseille School of Economics Ilot Bernard Dubois, 5-9 Boulevard Maurice Bourdet CS 50498, 13205 Marseille cedex 1, France.

${ }^{\dagger}$ Stanford University. dsmcaa@stanford.edu

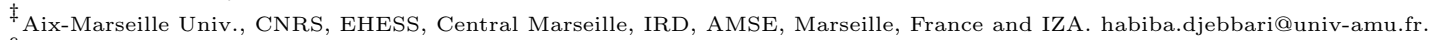

$\S$ Aix-Marseille Univ., CNRS, EHESS, Central Marseille, IRD, AMSE, Marseille, France. roberta.ziparo@univ-amu.fr
} 


\section{Introduction}

Smallholder agriculture represents 80 percent of all farms in Africa (AGRA, 2014). Yet, productivity levels are low, and progress has been slow (Wiggins, 2014). Small-scale farms are typically family-run businesses, very often with members of the farm household cultivating separate plots (Guirkinger and Platteau, 2015). Farm households are repeatedly found to make inefficient allocations of productive resources across plots, especially in West Africa. ${ }^{1}$ Most often, within-household misallocation is gendered, with too few inputs used on female-controlled plots (Doss, 2018). Yet little is known about the causes of these inefficiencies.

Determining the exact source of allocative inefficiency is key to designing solutions to raise the production capacity of farm households. While long-term interactions between spouses should offer an incentive to maximize household income (Browning, Chiappori, and Weiss, 2014), there is growing evidence that spouses hide actions or resources from each other (Anderson and Baland, 2002; Ashraf, 2009) and that they fail to communicate effectively (Ziparo, 2016; Ashraf, Field, Voena, and Ziparo, 2019). However, the extent to which asymmetric information is problematic in households has been questioned (Browning, Chiappori, and Lechene, 2010) ${ }^{2}$ and existing evidence on the role of private information in spouses' decisions is at best mixed (Mani, 2011; Kebede, Tarazona, Munro, and Verschoor, 2014). Recent contributions point to heterogeneity in response to private information - see, e.g. (Hoel, 2015) - but fall short of offering a theoretical framework to clarify the roles of private information and communication failure within the household.

To fill this gap, we investigate the farm household's capacity to reach efficiency and share information on the production side. We explore, both theoretically and empirically, the heterogeneity in responses to private information on production. To do so, we design an experiment, build a model consistent with the key findings from our experiment, and test the model's predictions further. To the best of our knowledge, this is the first paper to link heterogeneity in intrahousehold expenditure arrangements to the capacity to reach efficiency and share information in agricultural production. We highlight how conflict in consumption allocation impacts inefficiencies in production. We show that the extent of allocative inefficiency in production is heterogenous, like responses to information frictions and to increased returns on investment in the wife's plot. Our model suggests it is spouses' inability to communicate effectively that can generate an extra loss of efficiency under private information. When private information is verifiable ex post, there are no longer any extra losses in efficiency from information friction. We take these predictions back to the data and find evidence consistent with the theoretical predictions.

For our experiment, we build on standard lab-in-the-field games of resource-sharing within the household (Munro, 2018), adding an information component. The experiment, contextualized as an input allocation game, involves couples of Togolese cotton producers living in marital relationships. Each couple plays a series of two games. In all rounds, spouses can communicate prior to the decision, which is made privately by the husband. First, we ask each husband to decide whether to invest in his own plot of land with low returns or in his wife's land with high

\footnotetext{
${ }^{1}$ Following Udry (1996)'s seminal paper, evidence of allocative inefficiencies in agriculture was gathered by Akresh (2008) for Burkina Faso; Rangel and Thomas (2012) for Ghana and Senegal; Andrews, Golan, and Lay (2015) for Uganda; and Guirkinger, Platteau, and Goetghebuer (2015) for Mali.

${ }^{2}$ They argue that it "is probably less problematic in households than in other types of relationship (say, between employers and employees or insurers and insurees), because the very nature of the relationship often implies deep mutual knowledge and improved monitoring ability".
} 
returns but where the payoff will be hers rather than to his. Incentives are such that any deviation from allocating all of the endowment to his wife's land implies a loss of efficiency to the household.

We find that male farmers allocate too few inputs to their wife's plot in the game, failing to maximize household aggregate profits. We observe efficiency losses of 17.8 percent. In the second round, we triple the returns on investing in female-controlled plots. Men respond to increased returns from their wife's plot by investing more in it. In this second round, we also experimentally manipulate the information available to husbands. We randomly assign couples to one of three treatments: (1) full information, as in the base game, (2) hidden information, in which women are offered the opportunity to hide the true return from their husbands, (3) verifiable information, in which, while women can hide the true return from their husbands, the information is verifiable ex post. Private information held by women on their plots' returns has no effect on average on men's allocation decisions, whether or not this information is verifiable ex post.

In order to rationalize production inefficiencies, we investigate non-cooperative interactions between spouses. ${ }^{3}$ We propose a non-cooperative model of household production and consumption decisions and study conditions under which efficiency in production is reached under full information on returns from plots. The model is sequential. Men first decide how much to allocate to the female plot and then each spouse chooses his/her consumption bundle. Spouses jointly consume some household public goods, such as cooking, home maintenance, child care and education. Notably, preferences for these public goods differ across spouses. ${ }^{4}$ This has two important implications.

First, we show that even non-cooperative spouses find it optimal to maximize joint agricultural income when both contribute to the provision of a household public good (Bergstrom, Blume, and Varian, 1986). However, in equilibrium not all spouses in all households contribute to the provision of all goods. Three regimes of household behavior are obtained endogenously according to spouses' preferences and relative incomes: (1) a joint contributor regime in which both spouses choose to contribute to one public good, (2) a breadwinner regime in which only one of the spouses contributes to all public goods and (3) a specialization regime in which each chooses to contribute to separate public goods. ${ }^{5}$ Importantly, productive decisions critically depend on the regimes identified above: male farmers efficiently allocate inputs between their plot and their spouse's plot under the joint contribution regime, somewhat inefficiently under specialization and very inefficiently when they are the household breadwinners.

Second, when asymmetric information is added to the model, we show that it aggravates allocative inefficiency in production only under specialization, having no impact on households under joint contribution and on those with a breadwinner. We also show that, even though communication between spouses is possible, husband and wife do not communicate effectively

\footnotetext{
${ }^{3}$ In a static collective model, the household should maximize profit and then allocate consumption according to a sharing rule that cannot make one of the spouses better-off without making the other spouse worse-off (Browning, Chiappori, and Weiss, 2014). When limited commitment is introduced (Mazzocco, 2007; Voena, 2015), household members may renegotiate the sharing rule but production efficiency should be attained for those who remain in a cooperative equilibrium. An alternative model can take into account the endogeneity of spouses' outside options (Basu, 2006). The additional income gained in the experiment is too small for outside options to be affected. Thus, this alternative model cannot explain our experimental findings.

${ }^{4}$ Note that we do not stipulate the nature of the public good (children's education, home maintenance, etc.) for which preferences are heterogenous. This can differ across households or be dictated by a social norm.

${ }^{5}$ The specialization regime is akin to the separate-sphere regime described in Lundberg and Pollak (1993), but endogenously determined given spouses' preferences and relative incomes rather than dictated by social norms.
} 
and cannot avoid additional losses due to the information asymmetries. This, in turn, implies that ex post verifiability may help curb the extra loss from private information. If inefficiencies were rooted in difficulties enforcing a marital agreement, ex post verifiability would not be effective in limiting the deleterious effects of private information.

Our model predicts heterogeneity in the extent to which farm households make inefficient production choices under information asymmetries. We examine these predictions in the light of the experimental data, analyzing heterogeneity in the impact of our treatments across households. We classify households, albeit imperfectly, in three different regimes according to the choices made in the first round of the experiment: very efficient, somewhat efficient, very inefficient. We analyze how these different households respond to the information treatments in the second round of the experiment. Comparing choices made under the hidden and full information treatments, we find that the effects of asymmetric information are heterogenous. It is only the households that experienced the largest losses in the first round whose efficiency losses increase. These are a mix of breadwinners and households in the specialization regime. Since only the latter are expected to be affected, we obtain a lower-bound for households in the specialization regime. Comparing choices made under the verifiable and full information treatments, there is no heterogeneity in impact and none of three groups of households responds to the information friction. As predicted by the model, when spouses know that the information will be revealed ex post, information friction does not affect the efficiency of decisions.

This paper contributes to four strands of the literature. In the standard farm household model, households work as an economic unit making production and consumption decisions (Singh, Squire, and Strauss, 1986). When markets fail, these decisions are no longer separable (LaFave and Thomas, 2016), and production can no longer be treated as independent of household members' preferences. As such, the standard model predicts inefficient allocation of resources across households but efficient allocation within the household. Our contribution is to highlight other sources of inefficiency resulting in intrahousehold inefficient allocative decisions.

Within the theoretical literature on household decision-making, our model is closest to Browning, Chiappori, and Lechene (2010)'s model of consumption choices (BCL 2010). That paper extends Bergstrom, Blume, and Varian (1986) to a setting with many public goods. BCL (2010) find that, in general, household members will either specialize in the provision of certain household public goods or jointly produce at most one. (Only) in the latter case, spouses fully pool income as in Bergstrom, Blume, and Varian (1986). We add to BCL (2010) a production stage. We model households engaged in agricultural production, thereby endogenizing spouses' incomes generated from female- and male-controlled plots. Our results also relate to those of Doepke and Tertilt (2018), who extend BCL (2010) to an environment in which spouses incomes are endogenous to their time investments in public goods produced in the household. ${ }^{6}$

We also extend the analysis to a setting in which some information is privately held. By doing so, we contribute to the literature studying information frictions within the household. Fafchamps (2001) shows that information asymmetries reduce spouses' ability to enforce marital agreements . In contrast, we focus here on conditions under which agreements are self-enforced, exploring different regimes of decision-making. Household choices and responses to information

\footnotetext{
${ }^{6} \mathrm{As}$ in our model, when spouses specialize in the provision of different public goods, there is no income-pooling. However, given that their model exhibits a continuum of public goods each of which is infinitesimal, joint contribution to a public good is not sufficient to guarantee the neutrality of income redistribution in the family.
} 
asymmetries critically depend on the regime in which they operate. The heterogeneity predicted is in line with evidence from our experiment as well as with recent evidence found in other contexts (Angelucci and Garlick, 2016; Hoel, 2015; Hoel, Hidrobo, Bernard, and Ashour, 2017).

Finally, we extend the framework to allow for cheap talk between spouses. We contribute to a small and emerging literature on the role of communication within the household (Ziparo, 2016; Ashraf, Field, Voena, and Ziparo, 2019). In relation to this literature, our main contribution is to offer the first lab-in-the-field experiment testing cheap talk in the household. ${ }^{7}$ In our framework, communication between spouses cannot mitigate the additional efficiency loss from information asymmetries. This last result contrasts with predictions from a model in which spouses are involved in non-binding agreements (Fafchamps, 2001). According to our model, when information is verifiable ex post, even though privately held at the time of the decision, the husband can trust his wife to truthfully reveal it and the household should not suffer additional efficiency loss from the asymmetric information. The inefficiency will not be mitigated by ex post verifiability if instead the issue is imperfect enforcement of marital agreements. Moreover, the expected effect of ex post verifiability is limited to those households who operate in a separate-sphere regime. Our experimental findings from the verifiable information treatment are not consistent with the implications from a model of limited enforcement, but consistent with the prediction from our model.

To summarize, allocative inefficiency in production decisions may arise because of the nature of the intrahousehold decision-making process. Depending on spouses' preferences and their income gap, households may operate according to different behavior regimes. As a result, asymmetric information within the household will exacerbate inefficiency for some households but have no effect on others. Since the increase in efficiency loss under asymmetric information may be due to ineffective communication between spouses, it might be avoided if agricultural development programs targeting women also provided information to their spouses.

The rest of the paper is structured as follows. In the next section, we describe the sample and our experiment and present the key stylized facts gathered from it. In Section 3, we outline our model and describe its theoretical predictions. We test the heterogeneity in responses predicted by the model in Section 4 and we conclude in Section 5 .

\section{The setting, experimental conditions and preliminary evidence}

The objective of this section is to describe the experimental setting, data collection, experimental conditions and our main findings from the experiment. The experiment is designed as a game of input allocation across female- and male-controlled plots. It is similar to an investment game except that individual payoffs are made to each spouse separately. We expect three key factors to condition choices: returns on investment (inputs), private information held on these returns and communication between spouses. These key factors have also been addressed by other papers in the experimental literature (e.g. Ashraf, 2009; Kebede, Tarazona, Munro, and Verschoor, 2014; Hoel, 2015). Importantly, the use of lab-based findings to mirror real-life decisions in agriculture has found some support in the literature (Hoel, Hidrobo, Bernard, and Ashour, 2017).

\footnotetext{
${ }^{7}$ Ziparo (2016) studies theoretically cheap talk on income realizations between husband and wife. Ashraf, Field, Voena, and Ziparo (2019) is the first large-scale randomized controlled trial looking for causal evidence on the effects of communication failure in the context of household fertility choices.
} 


\subsection{Experimental setting and data collection}

The experiment was conducted in Togo, in the Plateaux Region. According to the most recent national census, 97 percent of the population in Togo is employed in agriculture, 51 percent of agricultural producers are female, and 82 percent of them live in households headed by a man (National Agricultural Census 2012-2014). The Plateaux Region is the main cash crop production area of the country, producing principally cotton along with coffee and cacao.

Participants were recruited with the help of Nouvelle Societe Cotonnaise du Togo (NSCT), in charge of organizing the cotton industry. Our sample was drawn from the latest census of cotton producers conducted in the region by NSCT, which identified 15,515 cotton producers, 1,081 of them women. ${ }^{8}$ We focused on couples both of whom are involved in cotton production, restricting to individuals aged 18 and above. After excluding polygamous households and couples residing in the remotest areas, our sample contained 150 couples out of the total population of 359 couples. This was reduced to a final sample size of 141 couples after verification of marital status.

The experiment took place in NSCT facilities and in school buildings located in five central localities in the region during October 2016. On each site, we interviewed participants from several surrounding villages. Each experimental session, followed by survey data collection, lasted for two hours. To avoid contamination of untreated households, we interviewed all participants from a given geographical area on the same day. Ten trained field experimenters supervized by one of the authors worked in pairs. ${ }^{9}$ Protocols were provided in both French and Ewe and field workers were also fluent in the other local languages (Ife, Moba, Lamba, Kotokoli and Kabye).

When participants arrived, husbands and wives were separated. They first received a show-up fee and were then invited to participate in the experiment. The allocation choices made by husbands during the experiment were recorded and are our main outcome of interest. Directly after completion of the experiment, a survey was administered separately to husbands and wives. After a short debriefing on the game, the survey included questions on demographics, assets, education, literacy/counting tests, occupations, social preferences and risk aversion. We also inquired about information-sharing within the couple, about who decides on how to exploit the individual's main plot and about who is responsible fot the main goods produced by the households and their main expenditures. Both male and female respondents also reported their individual share of broad categories of expenses.

We decided to study monogamous rather than polygamous households, knowing that only $17 \%$ of men aged 20-49 in Togo are polygamous (20 percent in the Plateaux Region). ${ }^{10}$ Our findings are thus representative of decision-making outcomes for 80 percent of men and women living in couples and producing cotton in the Plateaux Region.

\subsection{Sample description}

Tables 1 to 3 provide some summary statistics from our surveys. Table 1 shows that the couples are in a marital arrangement, with the male typically the head of household. Most couples are

\footnotetext{
${ }^{8}$ The census was presented at the NSCT board meeting in September 2016.

${ }^{9}$ Training of field experimenters and piloting of the experiment took a total of two weeks.

${ }^{10}$ These statistics are computed using DHS 2010 data.
} 
in a long-term relationship (average 19 years), with 4.8 children on average. ${ }^{11}$ There is a sevenyear age difference on average (men 44, women 37 years old). About 49 percent of both men and women attended or completed primary school. Though the level of literacy is higher for men than for women, both spouses scored high on numeracy. ${ }^{12}$ The spouses' income is spent on different household public goods: men spend more on health while women's spending is more food-related. Finally, there is some heterogeneity in living standards: just fewer than 10 percent experienced hunger in the three months prior to the survey, while more than half of them own a motorcycle.

Agricultural production is described in Table 2. Both males and females alike control the production of cotton on at least one plot belonging to the farm household. Average plot area controlled by females (males) is 1.74 (7.34) hectares. Men and women interpret "control of one's plot" differently. Roughly 66 percent of women consider that they control a plot only if they have total control over the income it generates and over input choices, while 19 percent equate control with controlling income. By comparison, 83 percent of men believe they need to control both income and inputs before they can consider the plot their own.

Consistent with evidence from other West African countries, information-sharing within the household is imperfect (Table 2). Though 74 percent (respectively 57 percent) of males (females) state that they have a good knowledge of the value of the produce from their spouse's main plot during the last agricultural season, 55 percent (respectively 46 percent) would still like to know more. Similarly, while a large proportion state that their spouse knows how much they produce on their main plot, about 40 percent still think their spouse would like to know more. Asymmetric information will be one of the key factors affecting input allocation choices that we will experimentally vary in the game.

Also consistent with evidence gathered in the sub-region (Doss, 2018), men are responsible for making input allocation decisions (Table 3). In fact, according to female respondents, most husbands have a say in the allocation of inputs to female-controlled plots. Men are in most cases the sole decision-makers. On average across the different types of inputs (domestic and hired labor, fertilizers and seeds) used on female plots, 61 percent of them make the allocation decision on their own, and 19 percent share the decision with their wife. On average, only 17 percent of females choose on their own the quantity of inputs used on their own plots. In the experiment and the model, men are responsible for the allocation of inputs across plots of land.

\subsection{Experimental conditions}

After receiving a show-up fee, participants were told they had the opportunity to earn more depending on the decisions made in a series of two games. These games were contextualized as input allocation games to place the subjects in familiar decision-making situations and to address the paper's research question.

It was the men who made the decisions. The womens' role in the games was to discuss the situation with their husbands prior to the decision. The men were told to decide how many of a total of 10 tokens (input units) to allocate to two boxes of different colors representing plots generating income for either husband or wife. A male participant had to decide whether to invest

\footnotetext{
${ }^{11}$ Husbands also have a non-negligible number of off-spring outside the official union: they have on average 2 children with other women, while the wives' average is 0.3 .

${ }^{12}$ Most of the game instructions were read out loud to allow for participants' varying litteracy skills.
} 
in his own plot of land with low returns or in his wife's land with high returns but a payoff to her and not him. We chose to have constant returns to scale production functions for the sake of simplicity. In all treatments, there was only one action that would maximize the household payoff: to allocate all inputs to the wife's plot.

\section{Treatments}

Base Treatment Figure 1 provides a reminder of the structure of the experiment. The base treatment (BT) took place during the first round under rules common to all participants. Importantly, in BT, all information was available to both husbands and wives. Choices made under BT allow us to test decision-making efficiency at the farm-household level and estimate efficiency losses under full information about returns. Given that the return on women's plots was twice as high as on men's plots, we have the following:

\section{Female Payoff $=2 y$ \\ Male Payoff $=10-y$}

where $y$ is the number of tokens allocated to the wife's plot. At BT, the efficiency loss, expressed as discarded surplus as a share of the maximum potential household earnings, can be written as follows:

$$
\text { Efficiency Loss }=1-\frac{10+y}{20}
$$

Each token had a value of 100 FCFA (about US $\$ 0.17$ ). Thus, for each token that a husband did not invest on his wife's plot, the household incurred a monetary loss of 100 FCFA. The maximum household surplus at BT was 2,000 FCFA, i.e. US $\$ 3.42$ at the current exchange rate.

Productivity Treatment The second-round game allows us to test if and how households react to (i) an increase in the returns on the wife's plot and (ii) information asymmetries. Between the first and second rounds, we increased the ratio of returns from two to three, and therefore call the second-round game "the productivity treatment", or PT. Given that the return on women's plots was now three times as high as on men's plots, we have the following:

$$
\begin{gathered}
\text { Female Payoff }=3 y \\
\text { Male Payoff }=10-y
\end{gathered}
$$

where again $y$ is the number of tokens allocated to the wife's plot. Thus, the efficiency loss in the second round can be written as follows:

$$
\text { Efficiency Loss }=1-\frac{10+2 y}{30}
$$

Marginal loss was higher in PT than in BT. For each token that husbands did not invest in the more productive female controlled plot, the household forwent 200 FCFA. The maximum household surplus at PT was 3,000 FCFA, i.e. US $\$ 5.14$ at the current exchange rate.

In addition to increasing returns from women's plots, we also randomly assigned couples to one of three treatments: 
1. a full information treatment in which the experimenter provided all the information on the returns (ET, for experimenter treatment),

2. a hidden information treatment (HT, for hidden treatment) in which the experimenter informed only the wife of the value of the return from her plot. Husbands received the information by their wives.

3. a verifiable information treatment in which husbands received the information from their wives but both knew that the experimenter would reveal the true returns after the decision was made (RT, for revealed treatment).

Treatment ET was designed like the base treatment, but with returns on investment in the wife's plot three times as high as on husband's plot. HT was very close in design to ET, except that women could strategically manipulate the information on returns from their plots. In ET (respectively HT), the experimenter (respectively the wife) was in charge of communicating this piece of information. RT was is very close in design to HT, except that the information was asymmetric prior to decision-making, although verifiable ex post. Note that in the information treatments (HT and RT), the experimenter told both spouses that the returns from female plots are at least as large were in the base treatment (BT). Appendix A provides a thorough description of the protocol.

\section{Communication}

Once they had received all the instructions and had shown that they understood them, husbands and wives were instructed to talk to each other for five minutes before the men made their decisions privately. In the real world, while women may have an informational advantage concerning returns from their own plots, spouses can be expected to talk about them. Indeed, communication between spouses may help them lessen the negative impact of the information asymmetry. In the experiment, we allowed time for pre-play communication between spouses in all treatments without monitoring their discussions.

\section{The issue of couples' lab behavior}

Because participants in our experiment live in a marital relationship, we face three key challenges. First, the behavior observed in the lab may be undone once the spouses leave the lab but continue interacting, making the experiment less informative. To obtain more reliable information, we gave the players the opportunity to hide their payoffs. We used two means: private payments to players and a system of lotteries that made it possible to conceal the exact value of payments received by male participants. Indeed, despite our privately-made payments, women could have guessed the decision simply from the amount paid directly to them. To avoid this, both husband and wife knew that their earnings would be partly determined by a series of two lotteries. The outcome of the first lottery would determine whether they were remunerated on the basis of decisions made in the first round or in the second round. The second lottery introduced a state of the world in which they might earn zero. However, expected earnings in each round would be equal to the 
payoffs without the lottery. ${ }^{13}$ Both spouses knew the basic structure of the lotteries, but wives could not observe their outcomes. ${ }^{14}$ As a result, wives are not able to infer from their gains their husband's decision and payoff. According to debriefing data, most women (53 percent) declared they did not know how much their husband earned in the lab; only 26 percent felt confident in predicting the men's earnings.

A final concern is specific to the hidden information treatment. Despite privately-made payments, women may not be able to hide their payoffs after stepping out of the lab. Husbands may force them to reveal how much they earned and could then learn whether their wife misreported information to them. The risk is that women may not correctly anticipate their husband behavior outside the lab (if they do, the threat should make them report truthfully the piece of information they hold). The risk that some women wrongly anticipate their husband response is probably low, but not null. Participants provided informed consent and were explicitly told they could leave the lab at any time and would still get to keep their show-up fee.

\subsection{A first look at the experimental evidence}

Table 4 compares investment decisions, efficiency losses and payoffs under each experimental condition.

Husbands in the first round (BT) were fully informed by the enumerators about the experimental conditions. Despite full information, we find that most failed to maximize aggregate profits (first column of Table 4). On average, they invested 6.42 tokens in their wife's plot, short of the optimal investment had they maximized household aggregate payoff (i.e., 10 tokens). Their decisions resulted in average earnings of 1,287 FCFA for their wives. Husbands decided to forgo 356 FCFA in aggregate earnings to the household in order to have full control of them. The decisions taken by the husbands yielded an average efficiency loss of 17.8 percent. Recall that two lotteries were run at the end of both rounds, enabling the husbands to hide their earnings from their wives (but not vice-versa). Forgoing aggregate income may thus be an optimal response when a marital agreement over the sharing of income is costly to enforce. If so, the aggregate earnings loss to the household would provide a measure of these transaction costs. ${ }^{15}$

Recall now that a randomly selected fraction of participants also experienced the full information condition in the second round (ET). Our findings for this group are qualitatively consistent with those under BT (second column of Table 4). Even under increased returns on investments in their wife's plot, men failed to maximize household aggregate output. In comparison to BT, they slightly increased the number of tokens they invested in their wife's plot to 6.72 . Their decisions also yielded significantly higher average earnings (2038 FCFA) by wives. Despite the increased investment in the wife's plot, however, aggregate losses to the household were significantly larger in both absolute and relative terms. Households under ET experienced an average efficiency loss of 21.3 percent, a significant 3.5 p.p. increase as compared to BT. In monetary terms, this represents an average of $641 \mathrm{FCFA}$ in forgone earnings to the household. ${ }^{16}$ Average male earnings

\footnotetext{
${ }^{13}$ With $50 \%$ chance of drawing round 1 or round 2 , maximum expected earnings are $(2,000+3,000) / 2=2,500$ FCFA, representing US $\$ 4.28$ at current exchange rate and PPP $\$ 11.64$. Estimated annual income per capita is $\operatorname{PPP} \$ 1,700$.

${ }^{14}$ See Appendix A for more details on the structure of the lotteries.

${ }^{15}$ On average, PPP $\$ 1.65$.

${ }^{16}$ That is PPP $\$ 2.97$.
} 
were 320 FCFA. This implies that, on average, men were willing to forgo 2 FCFA in aggregate household earnings for each additional FCFA over which they have full control.

More generally, when round 1 (BT) is compared to round 2 (PT), (last column of Table 4), investments in female-controlled plots are also seen to increase slightly on average, while efficiency loss significantly increases by 4 p.p. Male earnings significantly drop by an average 29 FCFA, while female earnings significantly increase by an average 730 FCFA. Between round 1 to round 2 , household aggregate earnings increase while, and at the same time, forgone household earnings also increase (average change in forgone earnings of +299 FCFA). The empirical distributions of transfers are shown in Figure 2. We observe 5 percent of the data at $B T=P T=10$ and no mass at $B T=P T=0$. The remaining 95 percent show intermediate values of transfers.

Experimental conditions in round 2 differ from those in round 1 along two dimensions: we increased the returns on investing in female-controlled plots and we manipulated the extent of information available about these returns. Nevertheless, differences in husbands' choices between ET and BT are driven only by the increased returns (see second paragraph in this section). ${ }^{17}$

We now focus on comparing the information treatments (HT and RT) to ET (columns 2, 3 and 4 of Table 4). The random assignment to treatment ensures that differences in choice can be attributed exclusively to the treatment conditions. Comparing HT to ET, we can isolate the effect of empowering women with a piece of information hidden (HT) from their husbands. Husbands knew the difference in returns in round 2 was at least as large as in round 1, but not precisely how much larger it was. The women were given this information, which they could attempt to communicate to their husbands before the men made the allocation decision. Surprisingly, in HT the hidden information has a small and statistically insignificant effect on the number of tokens men invest in female-controlled plots, on efficiency loss (statistically insignificant 1.8 p.p. effect) and on aggregate forgone earnings (statistically insignificant 27 FCFA increase). Condition RT is very similar to HT except that in RT both spouses knew that the private information woulds be revealed ex post. We find that the average effect of RT is also small and statistically insignificant. Thus, we can conclude that on average, the husbands were not influenced by the fact that their wives held private information, regardless of whether this private information was ex post verifiable.

To sum up, we find that increasing returns to investment in female-controlled plots leads to increased investment in these plots but also to increased efficiency losses. We find little average impact of information asymmetries on husbands input allocation choices.

It may be that our information treatments do not aggravate inefficiency if ex ante communication between spouses is effective in wiping out the asymmetry of information. Yet even in the absence of information frictions, we still observe large efficiency losses. How can allocative inefficiency under full information be explained? We conjectured that these inefficiencies may arise from difficulties enforcing a marital agreement over the sharing of income. But if this explanation were to hold, we would expect (1) information frictions to aggravate the inefficiencies, (2) ex post revelation to be ineffective in curbing the extra efficiency loss from the information friction. Our findings from the information treatments, however, are not consistent with this

\footnotetext{
${ }^{17}$ The difference could also capture changes associated with other factors that change with time. These would include learning effects. Since we had participants play several rounds for practice prior to round 1, we are reasonably confident that the learning took place during the practice rounds. Also, participants did not learn about other participants' behavior between rounds.
} 
explanation: we do not find that on average inefficiencies are exacerbated by in our different information treatments.

In the remainder of the paper, our objective is to offer an explanation for the observed efficiency losses under full information highlighting heterogeneity in responses to the treatment conditions. As we will see in section 3, the model provides clear predictions regarding optimal response to increasing returns and private information for different household arrangements. We test them in section 4 .

\section{Theoretical Framework}

In this section, we provide a theoretical framework rationalizing the key findings of the experiment. We analyze decision-making in the farm household with respect to the three key determinants - studied in the experiment - of the allocation of productive resources: returns on investment, private information about these returns and communication between spouses. Our model yields fine predictions on the effects of these factors: we obtain several testable predictions that allow us to go back to the data and test the validity of our theoretical framework.

\subsection{Benchmark model: full information}

Consider a married couple who has to decide both on the allocation of productive inputs and on expenditures, given individual preferences and individual budget constraints.

We assume that spouses farm separate plots $^{18}$ and that their individual income depends on an exogenous income $Y^{j}$ and on the produce from of the individual plots. We assume that the husband and the wife have different production technologies and that the input productivity on the husband's land is lower than on that of the wife. ${ }^{19}$ Thus, the agricultural income (assuming output prices normalized to 1) of the two spouses is:

$$
\begin{gathered}
I^{H}=f^{H}\left(x^{H}\right)=x^{H}, \\
I^{W}=f^{W}\left(x^{W}\right)=k x^{W},
\end{gathered}
$$

where $k$ is the difference in productivity between the husband and the wife and $x^{i}$ the amount of input on the plot of each spouse.

Assumption I: $k>1$.

Assumption 1 means that each unit of input used on a female-controlled plot generates more output than the same unit used on a male-controlled plot.

We also assume that the husband is the owner of the household's inputs $B$, and that he has to decide on how to allocate them across plots. Hence, depending on the allocation, husband and wife use the same input in different proportions. The only difference between their production technologies is the difference in marginal returns on investment. The total income of each spouse,

\footnotetext{
${ }^{18}$ The growing individualization of plots in farm households has been widely debated in the recent development literature. See Guirkinger and Platteau (2017) for a review.

${ }^{19} \mathrm{We}$ assume a linear production function for each spouse. This is a simplifying assumption: we assume that we are located on the side of the real production function where the wife's plot is more productive than her husband's. We thus use the linear approximation to simplify computations and match the experimental design.
} 
$R^{j}$, is given by:

$$
\begin{gathered}
R^{H}=Y^{H}+I^{H}=Y^{H}+(B-t), \\
R^{W}=Y^{W}+I^{W}=Y^{W}+k t,
\end{gathered}
$$

where $t \in[0, B]$ is the amount of inputs that the husband decides to invest in the wife's plot. The household's income is then $R^{H}+R^{W}$. We start by analyzing a problem where both the exogenous income and the productivity of the female-controlled plot of land are perfectly known. The efficient production decision is to allocate all the resources to the wife to use on her plot. This choice maximizes the household income available to finance both household public good provision and private consumption (See Appendix B.1 for the proof).

In our environment, husband and wife also have to decide on resource allocation across private consumption and public good provision. In developing countries, frequent income shocks, short life expectancy and strong gender norms may lead to commitment problems. ${ }^{20}$ Thus, we assume that the spouses behave non-cooperatively in the consumption decision process and we study the incentives to maximize productive income, given individual incentives for consumption. Our theoretical model is based on that of Browning, Chiappori, and Lechene (2010). A key assumption in this respect is that spouses have different relative preferences for the different public goods.

We assume the preferences of each spouse take the following form:

$$
U^{H}=\log \left(c^{H}\right)+\log \left(Q_{A}\right)+\log \left(Q_{B}\right)
$$

for the husband, and

$$
U^{W}=\log \left(c^{W}\right)+\alpha \log \left(Q_{A}\right)+\log \left(Q_{B}\right)
$$

for the wife, with $c^{j}$ the private consumption of each spouse $j=H, W, Q_{A}=q_{A}^{H}+q_{A}^{W}$ and $Q_{B}=q_{B}^{H}+q_{B}^{W}$ two continuous public goods, and with $q_{i}^{j}, i=A, B$ the individual contributions to those public goods. The contributions of the two spouses are perfect substitutes.

Assumption II: $\alpha>1$.

This assumption implies that the wife has a stronger preference for good $A$ than for good $B$ and a stronger preference than the husband for this good.

The individual budget of spouse $j$, given his/her income, is the following:

$$
R^{j}=c^{j}+q_{A}^{j}+q_{B}^{j}
$$

The intra-household input and consumption allocations are determined sequentially. First, the husband determines the optimal amount of transfers and then both spouses simultaneously decide on their contribution to the household public goods. We will thus solve the household's problem by backward induction. We first determine the optimal household consumption decisions as a function of transfers. Then we compute the optimal allocation of productive resources.

In the second stage, each spouse maximizes, for a given level of inputs to the wife's plot $(t)$, his/her own utility choosing his/her own level of private consumption $c^{j}(t)$ and own contribution to the public good $\left(q^{j}(t)\right)$, given own income $\left(R^{j}(t)\right)$ and taking as given the contribution of the other. The optimal consumption allocation allows us to define, for each spouse, his/her indirect

\footnotetext{
${ }^{20}$ See Baland and Ziparo (2018) for a richer discussion.
} 
utility $V^{j}$.

Then, in the first stage, the husband determines the optimal level of transfers, $t$, taking as given the intra-household equilibrium of the second stage. He maximizes:

$$
\max _{t} V^{H}(t)
$$

subject to $t \leq B$.

where $V^{H}(t)$ is the indirect utility of the husband.

Assumption III: $k<\bar{k}$.

We define $\bar{k}$ as the maximum level of productivity below which there is no change in public good contributions in the household. Given that our experiment induces only a marginal increase in productive inputs, we expect to observe no change in public good contribution regime in our experimental set-up. Moreover, in real life, the difference in input productivity is not very large.

Solving this problem by backward induction, we have the following proposition (see Appendix B.2 for the proof):

Proposition 1. Under Assumption I-III, there exist four threshold levels of the relative income $S=\frac{Y^{H}+B-t}{Y^{H}+B-t+Y^{W}+k t}$ of the two spouses that determine optimal public good contributions and transfers:

$\begin{array}{cccccc}\text { (i) } & q_{A}^{H}=q_{B}^{H}>0 & q_{A}^{W}=q_{B}^{W}=0 & t^{*}=0 & \text { for } & S>S_{4} \\ \text { (ii) } & 0<q_{A}^{H}<q_{B}^{H} & q_{A}^{W}>0, q_{B}^{W}=0 & t^{*}=B & \text { for } & S_{3}<S \leq S_{4} \\ \text { (iii) } & q_{A}^{H}=0, q_{B}^{H}>0 & q_{A}^{W}>0, q_{B}^{W}=0 & B>t^{*}>0 & \text { for } & S_{2}<S \leq S_{3} \\ \text { (iv) } & q_{A}^{H}=0, q_{B}^{H}>0 & q_{A}^{W}>q_{B}^{W}>0 & t^{*}=B & \text { for } & S_{1}<S \leq S_{2} \\ \text { (v) } & q_{A}^{H}=q_{B}^{H}=0 & q_{A}^{W}>q_{B}^{W}>0 & t^{*}=0 & \text { for } & S \leq S_{1}\end{array}$

As shown in the proof of proposition 1, the spouses' contributions to each public good depend on the relative total income (labor plus agricultural) of each spouse. In particular, we can define three regimes: the breadwinner regime (cases (i) and (v) above) arising when one spouse is richer than the other and he/she becomes the only contributor to both public goods; the jointcontribution regime (cases (ii) and (iv) above) when spouses contribute simultaneously to one of the two public goods when resources are asymmetrically distributed across spouses; the separate-sphere regime (case (iii) above) when spouses have comparable resources and each spouse specializes in his/her preferred public good.

When deciding the optimal allocation of resources, the husband takes into account which regime prevails in the second stage. When the husband is the breadwinner, the wife would rather spend her limited income on the consumption of a private good. As long as the change in productivity does not change the regime, there is no benefit to him from sharing even if told that the investment would be much more profitable on his wife's plot, as he expects her to spend any additional income on her own consumption.

When the joint-contribution regime kicks in, income neutrality allows spouses to reach productive efficiency. When the wife is not getting enough of her preferred public good from the contributions of her husband, she wants to supplement his contribution. Their joint provision creates a kind of income-pooling. Husbands therefore find it advantageous to make efficient farm 
decisions. $^{21}$

As the income gap between spouses decreases further, spouses may find it more advantageous to switch to a regime where each of them contributes to only one public good. A separate-sphere regime may arise when husband and wife care differently about distinct household public goods. As a man's income decreases relative to his wife's, he may be getting too much of his wife's preferred public good to equate the marginal utility he gets from this public good to the marginal utility he gets from consuming the other goods he cares about (private and public). He will thus prefer to contribute solely to his preferred public good. When each contributes separately to one public good, this will affect the husband's incentive to share any additional resources with his wife. She would spend the additional income not only on her private good but also on her preferred public good, from which he benefits too. However, he knows his wife cares more about this particular public good than he does, so he will not invest all of the extra resources in the wife's plot. Instead, he will invest in his wife's plot until he equalizes the marginal benefits he derives from each public good, which amounts to partial sharing. In addition, in this case, it is not enough for him to know that the returns from his wife's plot are much higher; he needs to know how much higher they are to find the optimal level of transfer.

\subsection{Unobserved wife's productivity and communication}

We have identified one source of production inefficiency in the conflicting interests behind consumption allocations. An additional source of inefficiencies may be information asymmetries. In particular, the husband may be poorly informed about how much more productive the wife's plot is compared to his own. Even if the wife has correct information about her agricultural returns, she may be unable to effectively communicate them to the husband, again due to conflicting interests in consumption.

Thus, in line with the experimental setting, we now study the equilibrium in transfers and public good provision when the wife's higher productivity is not completely observed by the husband. We assume that the husband knows that his wife's plot is more productive than his own, but not by how much $(k)$. The wife is completely informed, meaning she knows the value of both her productivity and her husband's. She is also aware that her husband does not have complete information.

Seeking to determine whether the wife's message about her productivity is credible to the husband, we introduce a communication phase that takes place before the transfer stage. Communication is costless (cheap-talk): the wife does not pay a direct utility cost for sending a particular message.

There are three stages to the game: in the first, the information transmission takes place; in the second, based on the signal given by the wife, the husband decides how much to transfer; in the third, both spouses contribute to the public goods and to private consumption. After the wife sends a signal $m$ to the husband with respect to her productivity, transfers followed by public good contributions take place.

We study the perfect Bayesian equilibrium of the three-stage game. The communication technology of the wife corresponds to all the possible $k$ belonging to its probability distribution $F(k)$ defined over the interval $M=\left[k^{L}, k^{H}\right]$ so that $M=\left[k^{L}, k^{H}\right]$ is the set of feasible signals.

\footnotetext{
${ }^{21}$ Given the game settings, they should transfer all of the resources to their wife.
} 
The equilibrium will consist of a family of signaling rules $h(m \mid k): \int_{M} h(m \mid k) d m=1$ and an equilibrium of transfers $t(m)$ and public good contributions $q(m)=\left(Q_{A}(m), Q_{B}(m)\right)$ such that:

$$
\max _{m} U^{W}\left(t(m), Q_{A}(m), Q_{B}(m) \mid k\right),
$$

and the husband solves:

$$
\max _{t} E\left[V^{H} \mid m\right]
$$

Solving this problem, and defining $S_{3}(I I)<S_{3}$ and $S_{4}(I I)<S_{4}$, the new threshold values under Incomplete Information, we have the following proposition (see Appendix B.2 for the proof):

Proposition 2. The perfect Bayesian equilibrium is characterized by the wife always sending a non-informative signal and the husband sending transfers as follows:

$$
\begin{aligned}
& \text { (i) } t^{* *}=0 \quad \text { for } \quad \frac{Y^{H}}{Y^{H}+Y^{W}+k^{H} B}>S_{4}(I I) \\
& \text { (ii) } \quad t^{* *}=B \quad \text { for } \quad S_{3}(I I)<\frac{Y^{H}}{Y^{H}+Y^{W}+k^{L} B}<\frac{Y^{H}+B}{Y^{H}+Y^{W}+k^{H} B} \leq S_{4}(I I) \\
& \text { (iii) } B>t^{* *}>0 \text { for } \quad \frac{Y^{H}}{Y^{H}+Y^{W}+k^{L} B} \leq S_{3}(I I)
\end{aligned}
$$

in case (iii) $t^{* *}<t^{*}$.

The signal does not affect the transfer; only income distribution between spouses and the productivity difference matter. The husband uses transfers as a means to balance the marginal utilities he derives from the two public goods. Thus, he transfers resources to his wife's plot because of her productivity advantage, so that she can finance her preferred public good. When there is high income inequality, only one spouse finances both public goods and there are no intra-household transfers. Conversely, when income inequality is low, each spouse specializes in the provision of one public good. Asymmetry of information on the wife's productivity has an effect on input allocation only in this situation. Because the husband does not observe his wife's productivity, he cannot anticipate how much she will invest in her preferred public good. Thus, unlike the case where there is perfect information, in this case he will decrease the amount of inputs transferred to his wife. ${ }^{22}$

The model yields clear predictions about the relationship between transfers and productivity in the household, and how asymmetries of information affect them. We can summarize these predictions as follows. First, we expect transfers to be "intermediate", meaning strictly between 0 and $B$, for households in which spouses have "separate spheres" when contributing to public goods. Second, the amount transferred increases when the wife's productivity increases. Third, the increase is lower when the husband does not observe the new level of productivity.

\subsection{Discussion: altruistic spouses.}

A natural extension of the paper would be to assume spouses are altruistic toward each other. Although there appears to be less room for altruism to reduce inefficiencies in developing countries than in developed ones due to the greater frequency of arranged and teenage marriages (see Baland

\footnotetext{
${ }^{22}$ Figure 1 summarizes the structure of the household decision-making process.
} 
and Ziparo 2018 for a discussion), it seems natural to assume some emotional attachment between spouses.

From a theoretical perspective, a level of altruism that would give equal weight to own consumption and to partner's consumption would imply an efficient level of contribution to public goods and, thus, efficient allocation of resources. As discussed for the cooperative case, we can rule out this hypothesis since a large part of the empirical evidence points to inefficiency in production. A low but positive level of altruism would imply a higher contribution to the public goods for both spouses, thereby reducing the probability that the household ends up in either the separate-sphere or the breadwinner regime (since the size of the intervals of relative income in which these regimes exist is reduced).

\section{Testing the model's predictions}

In section 2, we highlighted three key findings from the experiment. First, allocative inefficiency in production arises even when there are no information problems. Second, men respond to a rise in returns from female plots by increasing their allocation toward them. Third, on average, we find no impact from private information. In this section, we test two implications of our model regarding impact from private information. The first sub-section considers the heterogeneity in the impact from private information, first explaining how we test for it and then presenting our findings. In the second sub-section, we examine how ex post verifiability affect the impact of asymmetric information. The last sub-section provides some evidence for the external validity of our experimental findings.

\subsection{Testing for heterogenous response to asymmetric information}

We expect asymmetric information to aggravate allocative inefficiency in production under specialization but to have no impact on households under joint contribution and on those with a breadwinner. To test these predictions, we contrast choices under hidden treatment $(H T)$ - i.e., with female-held private information on the return from female-held plots - and under experimenter treatment $(E T)$ - i.e., under full information on returns. Importantly, while in section 2 we examined the average impact of asymmetric information and found none, here we identify differing impacts impact according to choices made in the first round of the game (base treatment or $B T)$. Asymmetric information should affect the households in the three regimes differently.

Breadwinner husbands are not expected to transfer any input under asymmetric information for the same reason they are not expected to transfer any under full information. This type knows that if his wife were to gain extra income, she would spend it entirely on her private good. We also expect no effect of asymmetric information for the joint contributors, because husbands should not care about the exact magnitude of the return: they just need to know that it is higher on their wife's plot. Since the women in these households contribute to (at least) one public good to which also the husbands contribute, husbands can recover a substantial amount of resources decreasing their public good allocation. Thus, men in joint contributor couples always benefit from making the efficient production allocation: provided they know that returns on their wife's plot are higher than their own returns, allocation will be efficient.

In contrast, we expect the husbands in the specialization regime to allocate less to their wife's 
plot under asymmetric information. In this regime, wives are expected to spend the additional income they could earn in the game on their preferred public good, from which their husband benefits, as well as on their private good. Because the husband knows that his wife cares more about a particular public good than he does, he does not transfer all of the extra resources to his wife's plot, but rather invests in his wife's plot until he equalizes the marginal benefits he derives from each public good, resulting in an inefficient production allocation even under full information. Importantly, it is not enough for him to know that the returns from his wife's plot are much higher, he needs to know how much higher they are in order to find the optimal level of transfer. Under asymmetric information, he expects his wife to have an incentive to overstate the extent of these returns in order to get a higher transfer. Thus he should respond to the information asymmetry by reducing the level of the transfer. Moreover, the asymmetric information treatment HT should have more impact on those who are farther from efficiency under full information.

One caveat is in order. Theory predicts that breadwinner husbands will choose $B T=P T=0$, those who jointly contribute to a public good with their wife will choose $B T=P T=10$ and households in a separate sphere regime will transfer some intermediate amount $0<B T<10$ and $0<P T<10$. However, our data contains no strict breadwinner couples and very few strict joint contributors (a total of 8). Indeed, if husbands hold social preferences (e.g., altruism, aversion to inequality), breadwinner husbands may decide to give a small amount to their wife and joint contributors to keep some for themselves.

We distinguish between 3 categories of households according to the number of tokens allocated to the wife's plot at $B T$. Variables $B T_{j}(j=1,2,3)$ distinguish between husbands who made low ( 4 or less for $j=1$ ), intermediate (from 4 to 6 for $j=2$ ) and high (6 or more for $j=3$ ) transfers to their wife at $B T .^{23}$

We first plot transfers in $E T$ and $H T$ according to the level of transfers at $B T$, as described above (Figure 3). Average transfers are similar in ET and $H T$ in the two top categories $(j=2,3)$ and lower in $H T$ than in $E T$ for the bottom category $(j=1)$.

Because breadwinners are not expected to be affected by asymmetric information, the estimated impact on the bottom category is interpreted to be a lower-bound for the effect of the information asymmetry on the separate-sphere type. Note that our findings are robust to a certain extent to the choice of thresholds in $B T$. Yet we have too few observations at $B T<1$ to distinguish the effects on breadwinners from those on separate sphere types.

We test for heterogenous impact as follows:

$$
Y_{i}=\alpha+\beta H T_{i}+\gamma \text { LowTransfersBT } T_{i}+\delta H T_{i} * \text { LowTransfersBT } T_{i}+\epsilon_{i}
$$

where $Y_{i}$ is the number of tokens transferred in either ET or $H T . H T_{i}$ is a dummy variable taking value 1 if spouses are randomly assigned to $\mathrm{HT}$ and 0 otherwise. LowTransfersBT $T_{i}$ is a dummy variable taking value 1 if the husband invested less than 5 tokens in the wife's plot at baseline. $\beta$ is the effect on those in the intermediate/high transfer categories at $B T(j=2,3)$. We expect no effect of the hidden treatment on them. We do expect $\delta<0$, i.e., a negative impact from the information friction for those who made low transfers at $B T$.

In Table 5 column 1 , we show that the impact of asymmetric information is small and insignif-

\footnotetext{
${ }^{23}$ We also discuss the robustness of the findings to the specific thresholds chosen for defining the categories.
} 
icant for those who made intermediate/high transfers at BT. Only those who made low transfers at $\mathrm{BT}$ respond to the information frictions and they do so by decreasing the transfer they make to the female-controlled plot by about 2 units of input (out of 10), a statistically significant drop. This drop yields an efficiency loss of about 13 percentage points, corresponding to about a 19 percent change. ${ }^{24}$ This effect, which was hidden when we looked at the average treatment effect, is consistent with our prediction that the information friction is detrimental only to separate-sphere households. The estimated effect is a lower-bound on the impact on separate-sphere households: the low transfers category is a mix of separate-sphere and breadwinner households.

\subsection{Testing for the effect of ex post verifiability}

What could be driving the efficiency loss experienced by separate-sphere households when information is asymmetric? To shed some light on this mechanism, we compare choices made under full private information (HT) to choices made when both spouses know that the information will be revealed ex post (RT). Recall that our experiment allows spouses to discuss together. This is especially true during the information treatments: the experimenter does not provide much information on returns on female-controlled plots, only indicating that they are at least as high as in the base treatment. According to our model, the detrimental effect of asymmetric information arises because spouses are unable to communicate effectively. When information is verifiable ex post, the cheap-talk game breaks down and wives in separate-sphere households have a strong incentive to truthfully reveal their returns as long as there is some social cost from lying. Empirically, this implies that we expect no difference between revealed treatment (verifiable information) and experimenter treatment (full information on returns) for the separate-sphere type. Or, equivalently, we should find that wives in separate-sphere households benefit from higher transfers under RT than under HT.

We find that when households made low transfers at BT, transfers under RT are significantly higher than transfers under HT (Figure 4). Using a variant of equation (1), we estimate the impact for those households. They are found to transfer about 2 units of input less (column 2 of Table 5), an effect which, as expected, is similar in magnitude to the one we find by comparing HT and ET for this same category of households (column 1 of Table 5). This effect is also statistically significant. Importantly, these households are the only ones affected by information verifiability: the impact of asymmetric information is small and insignificant for those who made intermediate/high transfers at BT. When RT and HT are compared, the estimated impact on those who made low transfers at BT can be interpreted as a lower-bound for the impact of information verifiability on separate-sphere households.

These findings are consistent with our model predictions: some households suffer an allocation efficiency loss due to information frictions, but this loss can be avoided when information is verifiable ex post, as women truthfully communicate with their husband about the true value of their returns. This points to communication failure between spouses as the source of the efficiency loss iunder private information.

An alternative explanation for the efficiency loss under private information is that spouses

\footnotetext{
${ }^{24}$ The decrease in efficiency for those who made low transfers at BT is $2 / 30 * 1.9=0.13$. Under full information $(H T=0)$, these households would experience an efficiency loss of 0.69 . The relative loss due to private information for these households is thus $0.13 / 0.69=0.18$.
} 
cannot perfectly enforce their agreements. If this were the case, however, we would expect all households to experience the same transfers on average under RT and under HT, including separate-sphere households. The impact on households would not depend on the level of transfers made in BT. Moreover, if limited enforcement were to blame for the extra efficiency loss due to the information asymmetry, information verifiability would not make a difference to any of the households.

For the sake of completeness, we also provide a comparison of transfers under ET and RT (Figure 5). As expected, there is no statistically significant difference in transfers for any of the types of households we identify based on the level of transfer at BT (Table 5 column 3 ).

To sum up, we find experimental evidence of inefficient allocation decisions, consistent with other findings based on observational studies. Moreover, we find two pieces of evidence consistent with the model's predictions. First, the efficiency loss due to asymmetric information differs in accordance to the behavior previously observed under full information. Specifically, the extra loss is concentrated among those showing strong inefficiency (transfers of 4 input units or less) in the base treatment. Since only households in a separate-sphere regime are expected to be affected by the information asymmetry, we interpret this effect as a lower bound of the effect on households. The heterogenous impact of asymmetric information is thus in line with the model's prediction.

Second, the experimental manipulation of verifiability has a heterogenous effect. This finding is not consistent with asymmetric information making it harder to enforce agreements, but is consistent with the model's prediction. For some households, agreements are self-supporting, and spouses do not need to be able to communicate about the exact value of returns from the wife's plot. For others (in a separate-sphere regime), failure to communicate could explain the extra loss incurred under information asymmetry.

\subsection{External validity}

To verify that our findings from the lab-in-the-field actually reflect the real-life decision processes of our sample of farmers, we use of survey data. As a proxy for the spouses' rival preferences, we examine whether spouses who have children from previous unions respond differently to the information treatments in the game.

We re-estimates columns 1 and 3 of Table 5 to study the heterogenous effect of the information treatment by number of children that either the wife or the husband had from previous unions (instead of the level of tranfers at baseline): columns 1 and 2 of Table 6 are in line with the model's predictions. First, private information does not affect game decisions when there are no other children from previous unions (lines 1). Second, when either the husband or the wife has children from other unions, the allocation to the wife decreases with each additional child from other unions (line 2). Efficiency losses are avoided when the information is ex post verifiable (columns 3 and 4 ).

\section{Conclusion}

Female farmers are typically engaged in agricultural production on the same farm as their spouse. The way spouses make decisions over consumption shapes their production decisions, which often results in a misallocation of resources across plots. Asymmetric information within the household 
may further exacerbate allocative inefficiency. Moreover, one may not be able to rely on effective communication between spouses to alleviate the information frictions.

We report results from a lab-in-the-field experiment on allocative investment choices by spouses. Our participant pool are couples of cotton farm producers in Togo and the game is mildly contextualized to refer to actual input allocation decisions across female-controlled and male-controlled plots. We provide new evidence of inefficient allocative investment choices by spouses, corroborating the extensive evidence on farm production inefficiencies when spouses cultivate separate plots stemming from Udry (1996)'s seminal paper. In addition, using the labin-the-field approach allows us to explore the determinants of these inefficiencies. We propose a theoretical framework that rationalizes the lab-in-the-field findings and leads to sharp predictions. In particular, we show both theoretically and empirically that there is substantial heterogeneity in the magnitude of losses across households, in their response to asymmetric information (from a treatment in which women are offered the opportunity to hide the true return on investment on their plot) and in the effect of information verifiability (from a treatment in which, while women can hide the true return from their husband, the information is verifiable ex post).

Our results call for caution in designing gender-sensitive agricultural policies as these may backfire depending on intrahousehold dynamics. Extra efficiency losses from ineffective communication may be avoided when agricultural programs that reach out to women also directly provide information to their spouses.

Our empirical results rely on lab-in-the-field data which may have limited external validity, though Hoel, Hidrobo, Bernard, and Ashour (2017) provide evidence supporting the use of labbased data for studying household behavior. ${ }^{25}$ Ashraf, Field, Voena, and Ziparo (2019) do find direct evidence that providing information on maternal health risk to husbands in Zambia is more effective than providing it to wives based on actual fertility behavior. A natural extension of our work would be to conduct a similar study looking at agricultural production decisions.

Another natural direction of research consists in extending the model to explore investment decisions of households with multiple businesses under the control of different members. Looking at male and female micro entrepreneurs belonging to the same household, Bernhardt, Field, Pande, and Rigol (2019) provide evidence that, though male- but not female-operated businesses benefit from access to business grants, there are income gains at the household-level that are independent of the gender of the recipient. Whether these investments are consistent with efficient allocative household decisions remains on open question.

\footnotetext{
${ }^{25}$ They do so by linking lab-based outcomes to actual real-life choices made outside the lab in the context of dairy farming in Senegal.
} 


\section{References}

AGRA (2014): "Africa agriculture status report: climate change and smallholder agriculture in sub-Saharan Africa.," Report, Alliance for a Green Revolution in Africa (AGRA).

Akresh, R. (2008): "(In)Efficiency in Intrahousehold Allocations," .

Anderson, S., and J.-M. Baland (2002): "The Economics of Roscas and Intrahousehold Resource Allocation," The Quarterly Journal of Economics, 117(3), 963-995.

Andrews, M. J., J. Golan, and J. Lay (2015): "Inefficiency of Male and Female Labor Supply in Agricultural Households: Evidence from Uganda," American Journal of Agricultural Economics, 97(3), 998-1019.

Angelucci, M., and R. Garlick (2016): "Heterogeneity in the efficiency of intrahousehold resource allocation: Empirical evidence and implications for investment in children," Discussion paper, Working Paper.

Ashraf, N. (2009): "Spousal control and intra-household decision making: An experimental study in the Philippines," The American Economic Review, pp. 1245-1277.

Ashraf, N., E. Field, A. Voena, and R. Ziparo (2019): "Maternal Mortality Risk and the Gender Gap in Desired Fertility," Manuscript.

BALAND, J.-M., AND R. ZIPARO (2018): Intra-household bargaining in poor countriesOxford University Press.

BAsu, K. (2006): "Gender and say: A model of household behaviour with endogenously determined balance of power," The Economic Journal, 116(511), 558-580.

Bergstrom, T., L. Blume, and H. Varian (1986): "On the private provision of public goods," Journal of Public Economics, 29(1), 25-49.

Bernhardt, A., E. Field, R. Pande, and N. Rigol (2019): "Household Matters: Revisiting the Returns to Capital among Female Microentrepreneurs," American Economic Review: Insights, 1(2), 141-60.

Browning, M., P.-A. Chiappori, and V. Lechene (2010): "Distributional effects in households models: separate spheres and income pooling.," The Economic Journal, 120(545), 786799 .

Browning, M., P.-A. Chiappori, and Y. Weiss (2014): Economics of the Family, no. 9780521795395 in Cambridge Books. Cambridge University Press.

Doepke, M., And M. Tertilt (2018): "Does Female Empowerment Promote Economic Development?," Working Paper 19888, National Bureau of Economic Research.

Doss, C. (2018): "Women and Agricultural Productivity: Reframing the Issues," Development Policy Review, 36(1), 35-50. 
Fafchamps, M. (2001): Intrahousehold Access to Land and Sources of Inefficiency: Theory and Concepts Oxford Scholarship Online.

Guirkinger, C., and J.-P. Platteau (2015): "Transformation of the family farm under rising land pressure: A theoretical essay," Journal of Comparative Economics, 43(1), 112-137.

Guirkinger, C., J.-P. Platteau, and T. Goetghebuer (2015): "Productive inefficiency in extended agricultural households: Evidence from Mali," Journal of Development Economics, $116(\mathrm{C}), 17-27$.

Hoes, J. B. (2015): "Heterogeneous households: A within-subject test of asymmetric information between spouses in Kenya," Journal of Economic Behavior 86 Organization, 118(C), $123-135$.

Hoel, J. B., M. Hidrobo, T. Bernard, and M. Ashour (2017): "Productive inefficiency in dairy farming and cooperation between spouses: Evidence from Senegal," IFPRI discussion papers 1698, International Food Policy Research Institute (IFPRI).

Kebede, B., M. Tarazona, A. Munro, and A. Verschoor (2014): "Intra-household Efficiency: An Experimental Study from Ethiopia," Journal of African Economies, 23(1), 105-150.

LaFave, D., and D. Thomas (2016): "Farms, Families, and Markets: New Evidence on Completeness of Markets in Agricultural Settings," Econometrica, 84(5), 1917-1960.

Lundberg, S., And R. A. Pollak (1993): "Separate Spheres Bargaining and the Marriage Market," Journal of Political Economy, 101(6), 988-1010.

Mani, A. (2011): "Mine, Yours or Ours? The Efficiency of Household Investment Decisions: An Experimental Approach," Cage online working paper series, Competitive Advantage in the Global Economy (CAGE).

Mazzocco, M. (2007): "Household Intertemporal Behaviour: A Collective Characterization and a Test of Commitment," Review of Economic Studies, 74(3), 857-895.

Munro, A. (2018): "Intra-household experiments: A Survey," Journal of Economic Surveys, $32(1), 134-175$.

Rangel, M. A., and D. Thomas (2012): "Gender, production and consumption: Allocative efficiency within farm households," Photocopy, Princeton University.

Singh, I., L. Squire, and J. Strauss (1986): "A Survey of Agricultural Household Models: Recent Findings and Policy Implications," The World Bank Economic Review, 1(1), 149-179.

Udry, C. (1996): "Gender, Agricultural Production, and the Theory of the Household," Journal of Political Economy, 104(5), 1010-1046.

Voena, A. (2015): "Yours, Mine, and Ours: Do Divorce Laws Affect the Intertemporal Behavior of Married Couples?," American Economic Review, 105(8), 2295-2332.

Wiggins, S. (2014): “African Agricultural Development: Lessons and Challenges," Journal of Agricultural Economics, 65(3), 529-556. 
Ziparo, R. (2016): "Why do spouses communicate: love or interest? A model and some evidence from Cameroon," Manuscript. 


\section{$6 \quad$ Tables and Figures}

Table 1: Socio-economic background

\begin{tabular}{|c|c|c|c|}
\hline & & Men & Women \\
\hline \multirow{2}{*}{\multicolumn{2}{|c|}{ Head of household/spouse }} & .94 & .96 \\
\hline & & $(.23)$ & $(.18)$ \\
\hline \multirow[t]{2}{*}{ Age } & & 43.94 & 37.15 \\
\hline & & $(1.1)$ & $(1.2)$ \\
\hline \multicolumn{4}{|l|}{ Education level (\%) } \\
\hline & No formal schooling & 17.73 & 43.26 \\
\hline & Primary level & 34.75 & 45.39 \\
\hline & Completed primary level & 13.48 & 4.26 \\
\hline & Middle-secondary level & 26.95 & 6.38 \\
\hline & Completed middle-secondary level & 2.84 & .71 \\
\hline & High school & 3.55 & 0 \\
\hline & Higher education & .71 & 0 \\
\hline \multicolumn{4}{|l|}{ Test scores (over 10) } \\
\hline & Reading & 6.63 & 2.24 \\
\hline & & $(4.62)$ & $(4)$ \\
\hline & Writing & 6.12 & 2.96 \\
\hline & & $(4.47)$ & $(4.20)$ \\
\hline & Counting & 9.64 & 8.12 \\
\hline & & $(1.85)$ & $(3.84)$ \\
\hline & Numbers reading & 7.5 & 3.93 \\
\hline & & $(3.98)$ & $(4.71)$ \\
\hline \multirow[t]{2}{*}{ Number of children with partner } & & 4.75 & \\
\hline & & $(2.01)$ & \\
\hline \multirow[t]{2}{*}{ Number of children with others } & & 2.02 & 0.3 \\
\hline & & $(3.58)$ & $(1.06)$ \\
\hline \multicolumn{4}{|l|}{ Primary spending $(\%)$} \\
\hline & Food & 21.28 & 34.75 \\
\hline & Schooling & 29.08 & 22.7 \\
\hline & Children's health & 39.72 & 19.15 \\
\hline & Other & 9.93 & 23.4 \\
\hline \multirow[t]{2}{*}{ Household size } & & 8.76 & \\
\hline & & $(4.1)$ & \\
\hline \multirow[t]{2}{*}{ Years in marital union } & & 19.01 & \\
\hline & & $(8.98)$ & \\
\hline \multirow[t]{2}{*}{ Own a bicycle } & & .44 & \\
\hline & & $(.50)$ & \\
\hline \multirow[t]{2}{*}{ Own a motorcycle } & & .53 & \\
\hline & & $(.50)$ & \\
\hline \multirow[t]{2}{*}{ Experienced hunger in the last 3 months } & & .08 & \\
\hline & & $(.28)$ & \\
\hline
\end{tabular}

Source: Authors' computations from own data sources 
Table 2: Agricultural production

\begin{tabular}{|c|c|c|c|}
\hline & & Men & Women \\
\hline \multirow[t]{2}{*}{ Total plot area farmed (in ha) } & & 7.34 & 1.74 \\
\hline & & $(6.98)$ & $(1.96)$ \\
\hline \multicolumn{4}{|l|}{ Main plot } \\
\hline & Control over income and input (\%) & 82.9 & 65.9 \\
\hline & \multirow[t]{2}{*}{ Own time spent per week (hrs) } & 33.47 & 26.14 \\
\hline & & $(11.2)$ & $(11.1)$ \\
\hline & \multirow[t]{2}{*}{ Spouse's time spent per week (hrs) } & 22.98 & 16.46 \\
\hline & & $(13.94)$ & $(12.56)$ \\
\hline \multicolumn{4}{|c|}{$\begin{array}{l}\text { Value of production from spouse's main plot } \\
\text { (last season) }\end{array}$} \\
\hline & Mostly know (\%) & 73.75 & 57.44 \\
\hline & Wants to know more $(\%)$ & 55.31 & 46.1 \\
\hline \multicolumn{4}{|c|}{$\begin{array}{l}\text { Value of production from one own's plot } \\
\text { (last season) }\end{array}$} \\
\hline & Believe sp. mostly know (\%) & 83.45 & 81.56 \\
\hline & Believe sp. wants to know more (\%) & 43.26 & 39 \\
\hline
\end{tabular}

Source: Authors' computations from own data sources

Table 3: Control over decision on inputs allocation to female plots (\%)

\begin{tabular}{lccc}
\hline & Women Only & Men Only & Jointly \\
\hline Family labor & 17 & 63.1 & 19.1 \\
Hired labor & 7.1 & 64.5 & 20.5 \\
Fertilizer & 17 & 63.8 & 18.4 \\
Seeds & 27.6 & 53.2 & 18.4 \\
\hline \hline
\end{tabular}

Source: Authors' computations from own data sources 


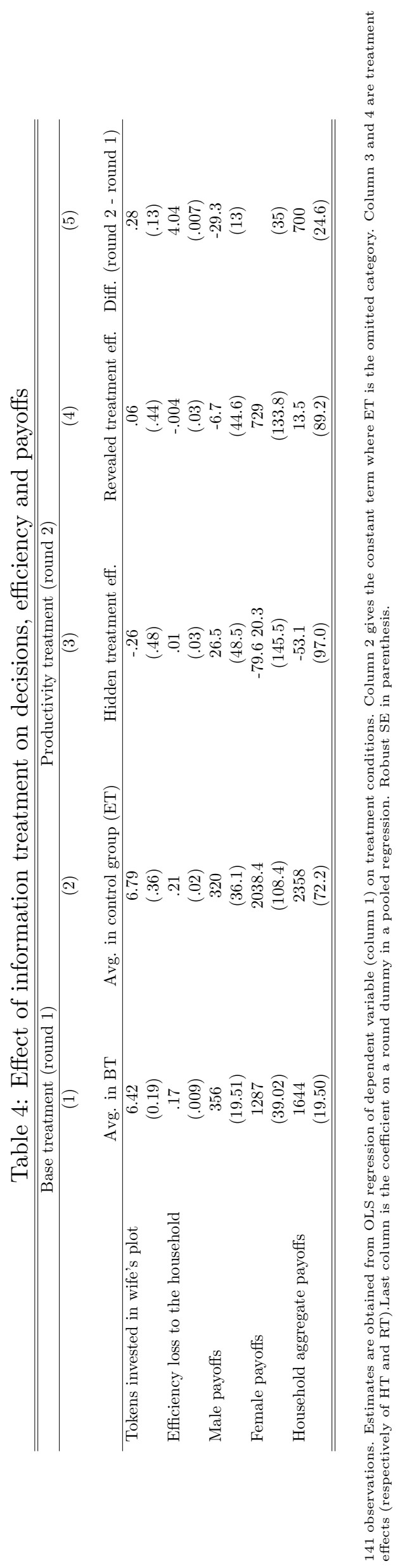


Table 5: Estimation of the effects of the information asymmetry on transfers: heterogenous effects in relation to past transfers.

\begin{tabular}{lccc}
\hline \hline & $(1)$ & $(2)$ & $(3)$ \\
& HT vs ET & HT vs RT & ET vs RT \\
\hline Direct effect & .29 & .40 & .11 \\
& $(.45)$ & $(.35)$ & $(.45)$ \\
Low transfers at BT & -1.87 & -1.91 & -1.91 \\
& $(.83)$ & $(.80)$ & $(.80)$ \\
Interaction w/ low transfers at BT & -1.90 & -1.86 & .03 \\
& $(.97)$ & $(.94)$ & $(1.15)$ \\
Intercept & 7.27 & 7.16 & 7.16 \\
& $(.37)$ & $(.25)$ & $(.25)$ \\
\hline Obs. & 90 & 102 & 90 \\
\hline \hline
\end{tabular}

Robust SE in parenthesis.

Table 6: Estimation of the effects of the information asymmetry on transfers: heterogenous effects in relation to children from previous unions

\begin{tabular}{lcccc}
\hline \hline & \multicolumn{2}{c}{ HT vs ET } & \multicolumn{2}{c}{ RT vs ET } \\
& Wife's child. & Husband's child. & Wife's child. & Husband's child. \\
\hline HT & -.09 & .06 & & \\
& $(.50)$ & $(.55)$ & & \\
HT* & -.71 & -.22 & & \\
Children & $(.27)$ & $(.12)$ & .19 & .20 \\
RT & & & $(.46)$ & $(.50)$ \\
& & & -.36 & -.11 \\
RT* & & & $(.28)$ & $(.11)$ \\
Children & & & 90 & 90 \\
\hline Obs. & 90 & 90 & &
\end{tabular}


Figure 1: Structure of the decision making process in the household

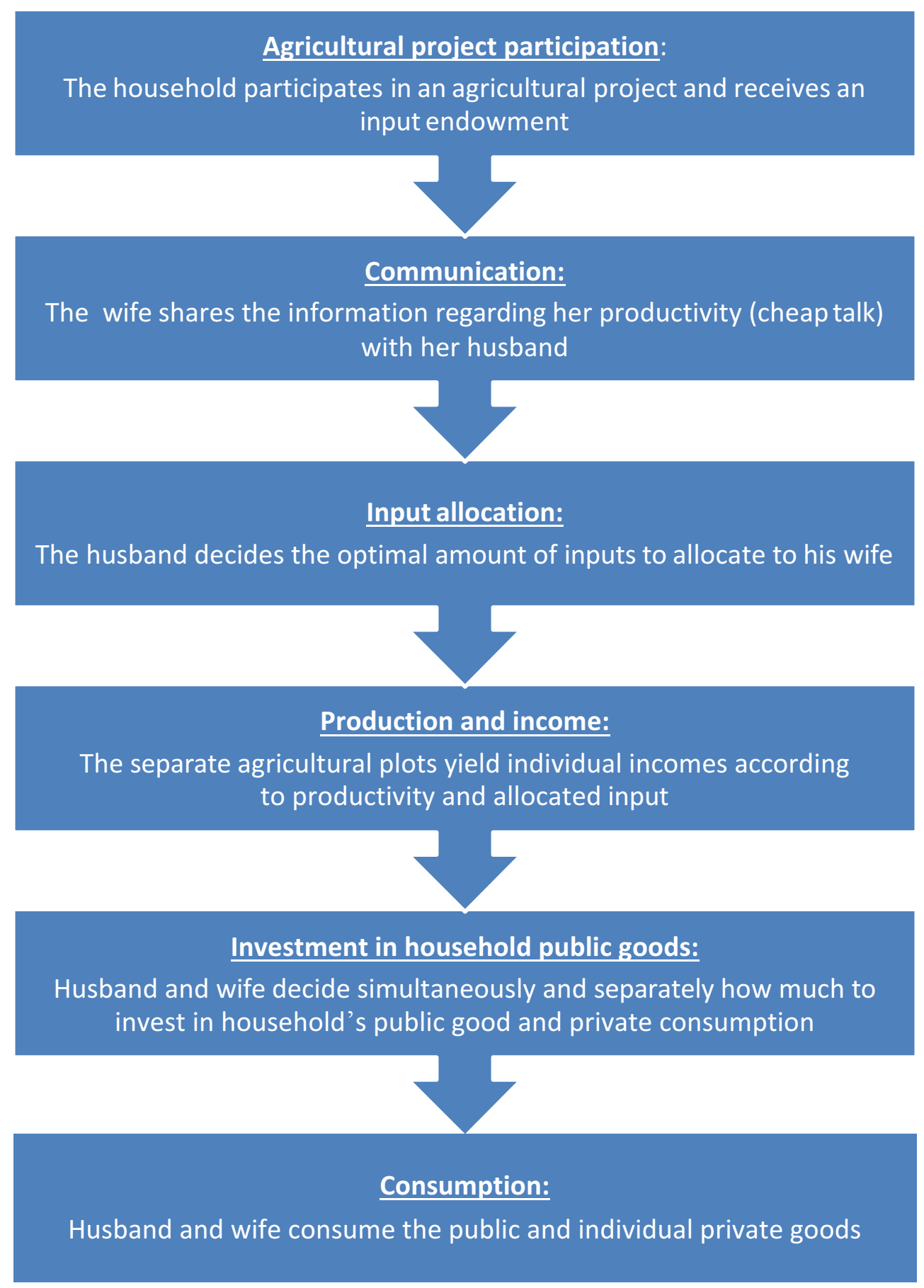


Figure 2: Distribution of transfers
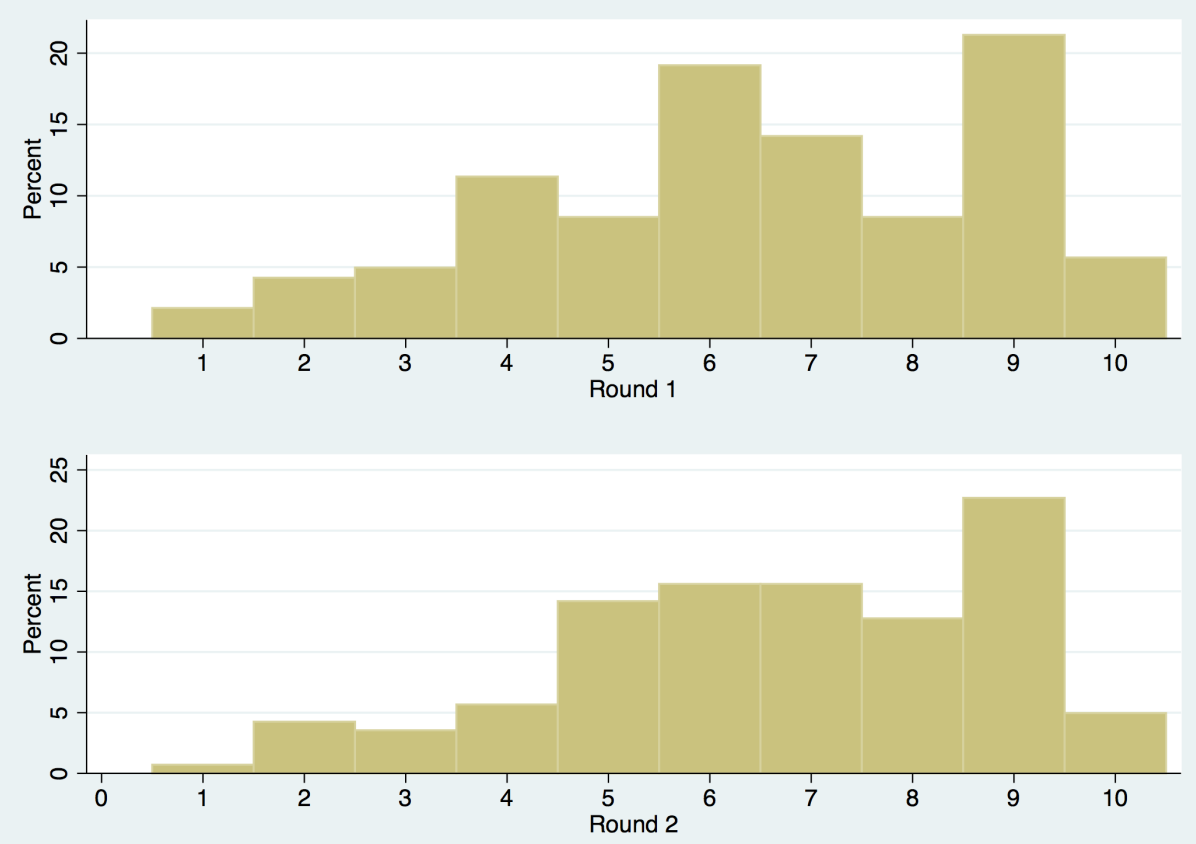

Source: Own data sources

Figure 3:

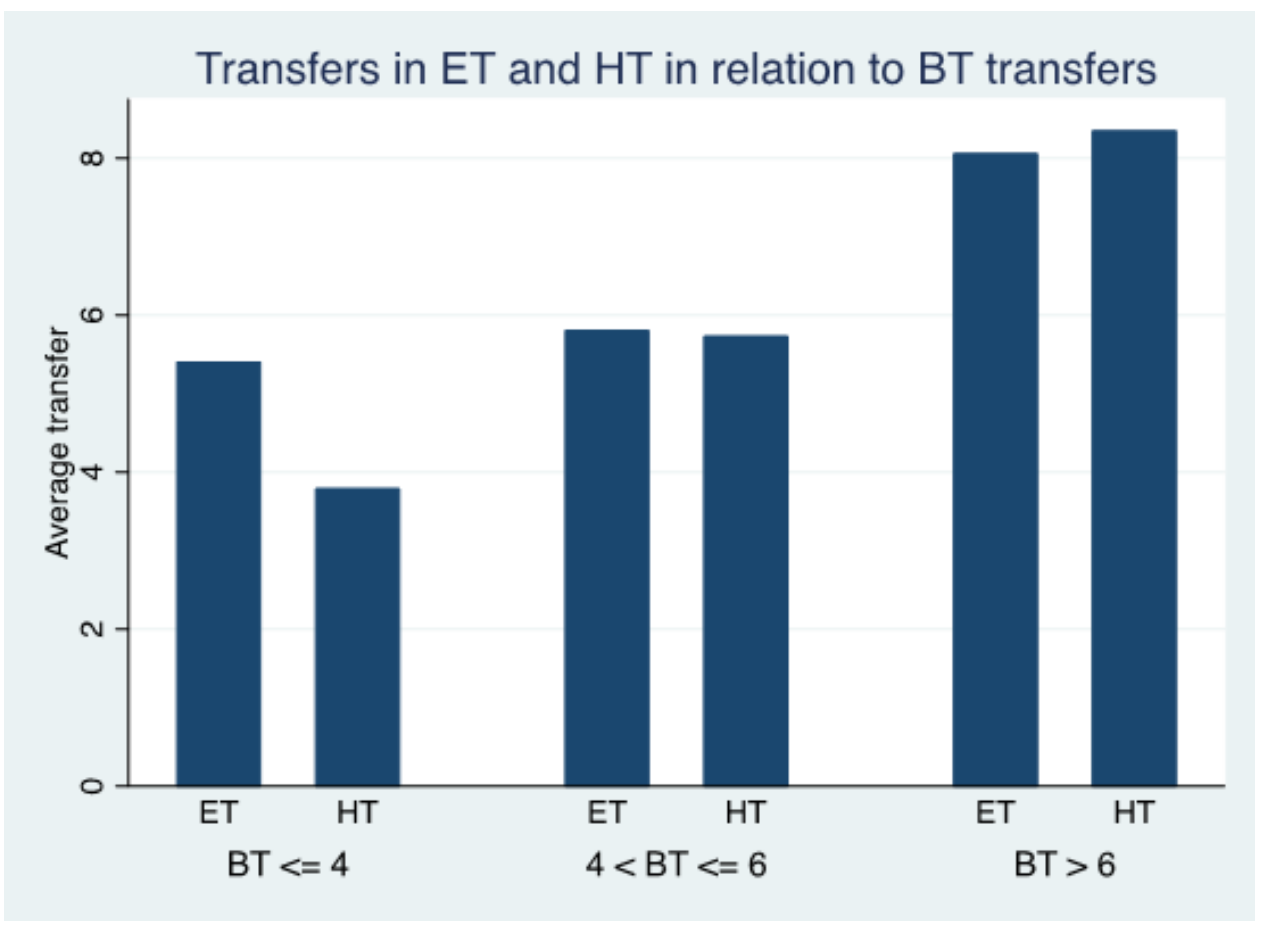

Source: own data sources 
Figure 4:

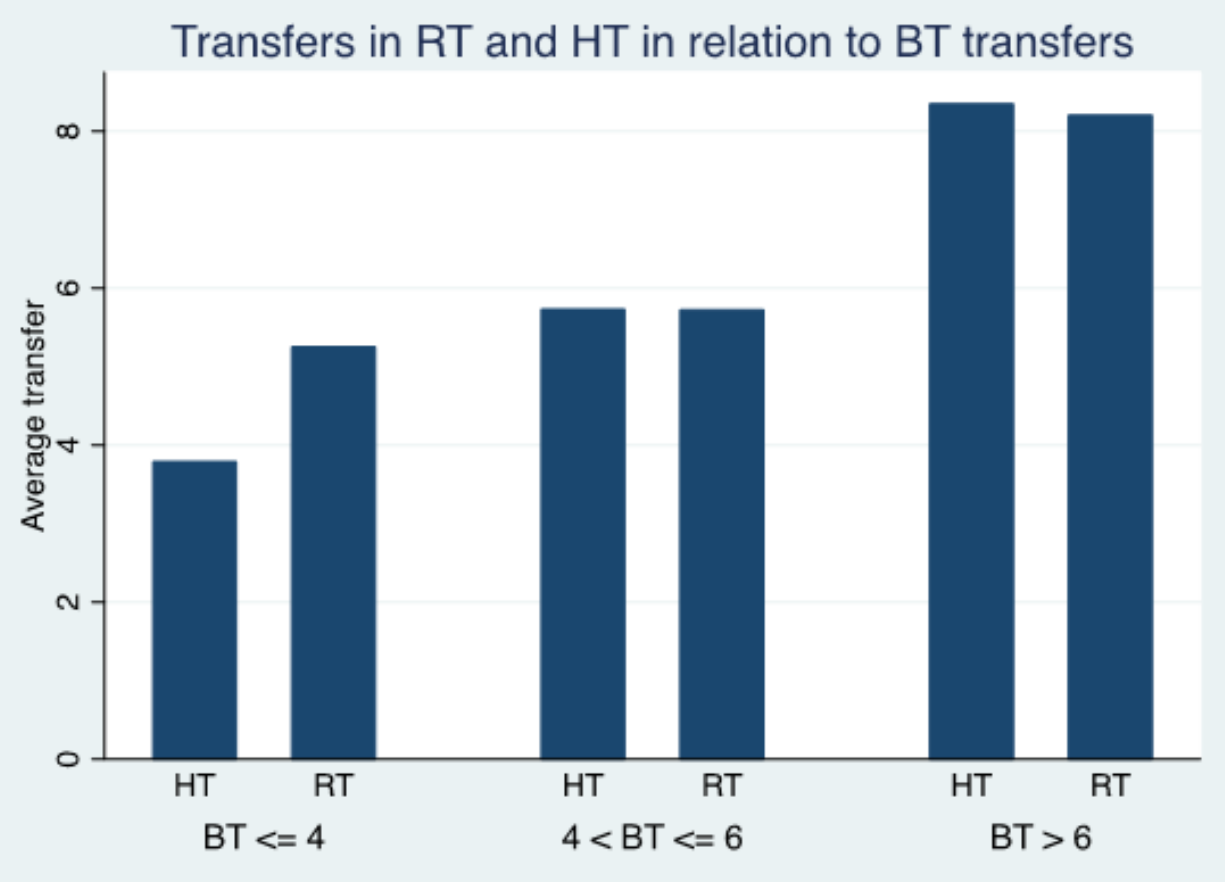

Source: own data sources

Figure 5:

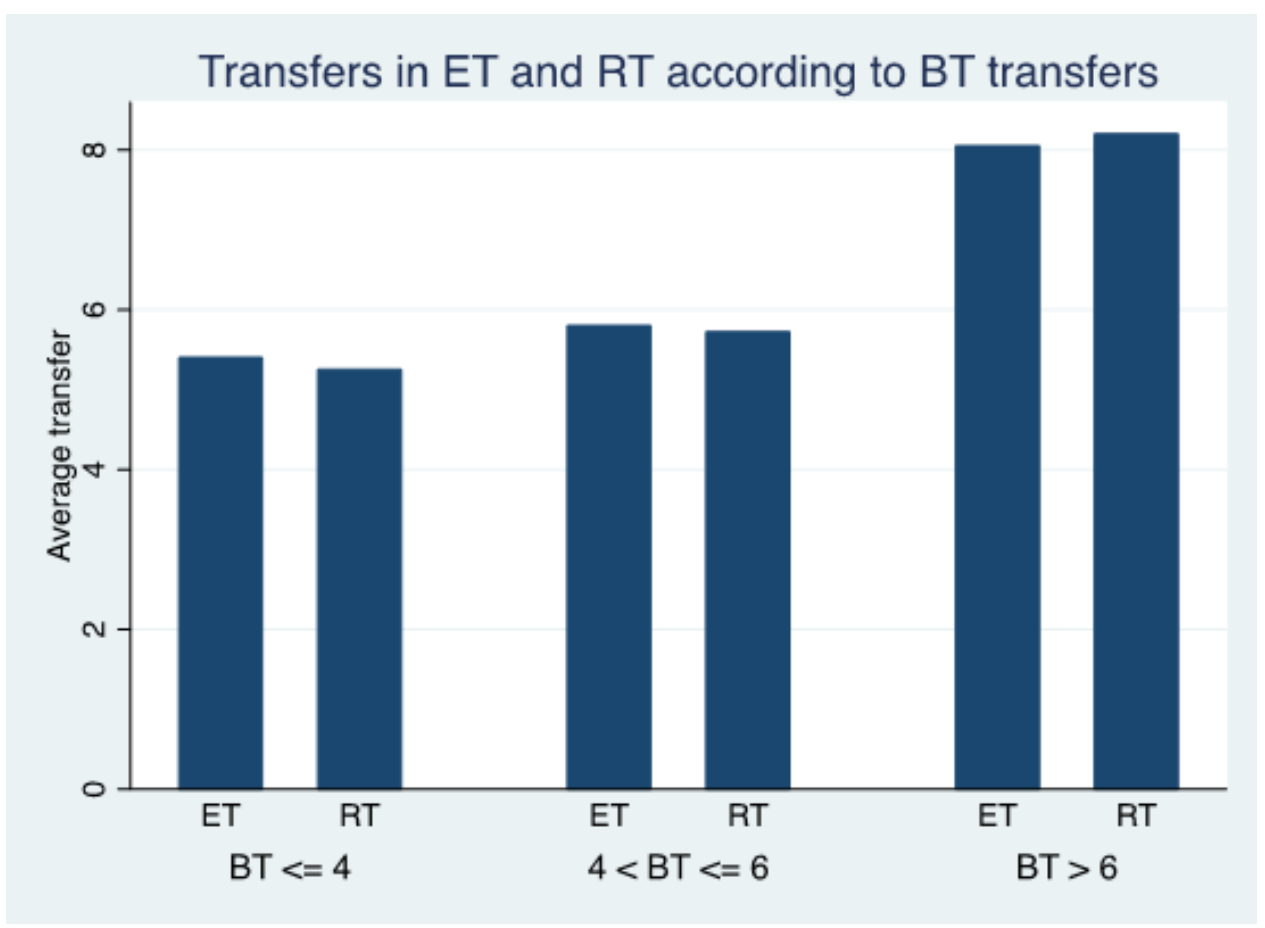

Source: own data sources 
Gender, information and the efficiency of household production decisions: An experiment in rural Togo

Online Appendix

September 17, 2019 


\section{A Experimental Design}

The following is a brief description of the experimental games, with a summary of the protocols (full version available in French and Ewe upon request).

Context and general instructions Each couple is invited to participate in 2 games. Game 1 ( $B T$ in the text) is the same for everyone. Subsequently 3 versions of Game 2 (ET, RT and $H T$ in the text) are randomly assigned. At registration, each couple receives an identification tag featuring the letter corresponding to their Game 2 assignment and their order of arrival.

Husbands and wives are placed in separate areas and assigned individual experimenters. To ensure confidentiality, experimenter-participant pairs are situated beyond hearing distance of each other. During the experiment, each experimenter reads the instructions aloud, explains them and tests the participant's understanding with questions. The game moves on only after each participant provides correct answers to all questions.

Participants are told they can each earn money during the games, the amount they receive being based both on the decisions made by the husband during the games and on the outcomes of two lotteries. These lotteries take place at the end of the games. The first lottery determines whether game 1 gains or game 2 gains will apply.The second lottery can increase or decrease the amount selected in the first lottery - there is even a chance of earning nothing. To place the second lottery in a realistic context, the experimenter refers to uncertainty in agricultural production related to unexpected events (weather, pests) that may act as positive or negative shocks and reminds participants how, when these events are extreme, farmers may lose everything.

Both husbands and wives know that their gains will be partly determined by the lotteries. Altough they know the basic structure of the lotteries, the wives are not invited to observe the lottery outcome. Payments are made in an individual and confidential way to each spouse. The husbands are informed that no one, including their wife, will know or can guess the decision they made and how much they will earn. The wives are informed that no one, except their husband, will know or can guess how much they will earn.

Game 1 (Base Treatment, same for all): Both men and women know the following:

- There are two separate plots of farmland. The woman is responsible for one of them, the man for the other.

- They have an endowment of 10 units of input to allocate between the two plots.

- Returns on each plot are constant, but they are twice as high on the female's plot as on the male's. In other words, yields increase linearly with the amount of input units used on each plot, but the increase is twice as high on the female's plot as on to the male's.

- They can talk freely for 5 minutes after they receive all instructions.

- The husband makes the allocation decision. He makes this decision privately after the couple's discussion.

- The husband is informed of potential gains from game 1 for himself and for his wife. Women neither observe nor are told about their husband's choice. They are not told how much they can earn from game 1.

- Both will take part in game 2.

\section{Game 2}


Experimenter Treatment (ET) Same as Base Treatment $(B T)$, the only difference being that now the returns from the female's plot are three times higher than from the male's. Participants are explicitly told that this is the only difference from the previous game. The experimenter reads the instructions and tests understanding. The men make a decision. As in $B T$, each man knows the potential gains he and his wife may make from game 2. As in $B T$, the women do not.

Hidden Treatment (HT) There are two differences from $B T$ that both members of the couple are informed of:

1. The experimenter tells the husbands that returns on their wife's plot are at least as large as in game 1 and that the returns on their own plot are unchanged.

2. The wife, rather than the experimenter, is now in charge of communicating the information on the returns from her plot.

As in $B T$, each man knows the potential gains he and his wife can make from game 2. As in $B T$, the wives do not, nor do they know the decision made by their husband.

Revealed Treatment (RT) There are three differences from $B T$ that both members of the couple are informed of:

1. The experimenter tells the husbands that returns on their wife's plot are at least as large as in game 1 and that the returns on their own plot are unchanged.

2. The wife, rather than the experimenter, is now in charge of communicating the information on the returns from her plot.

3. Both male and female participants know that the husbands will learn from the experimenters the returns on their wife's plot once they have made their allocation decision.

As in $B T$, each man knows the potential gains he and his wife can make from game 2. As in $B T$, the wives do not, nor do they know the decision made by their husband.

\section{B Theoretical Appendix}

\section{B.1 Cooperative decision-making}

\section{B.1.1 Optimal consumption allocations}

We define $\gamma$ as the pareto weight of the wife and $(1-\gamma)$ that of the husband. Thus, the household maximization problem is the following:

$$
\operatorname{Max} \gamma U_{i}^{W}+(1-\gamma) U_{i}^{H}
$$

which gives the optimal consumption levels:

$$
\begin{gathered}
Q_{A}^{*}=\frac{1+(\alpha-1) \gamma}{3+(\alpha-1) \gamma}\left(Y^{H}+Y^{W}\right) \\
Q_{B}^{*}=\frac{C^{* W}}{\gamma}=\frac{C^{* H}}{(1-\gamma)}=\frac{1}{3+(\alpha-1) \gamma}\left(Y^{H}+Y^{W}\right)
\end{gathered}
$$

\section{Optimal transfers}

In this case the indirect utility of the husband is:

$$
\begin{array}{r}
V^{H}(t)=\log \left(\frac{1+(\alpha-1) \gamma}{3+(\alpha-1) \gamma}\left(Y^{H}+B-t+Y^{W}+k t\right)\right)+ \\
(2-\gamma) \log \left(\frac{Y^{H}+B-t+Y^{W}+k t}{3+(\alpha-1) \gamma}\right)
\end{array}
$$


This is clearly maximized for $t^{*}=B$.

\section{B.2 Proofs}

\section{Proof. Proposition 1}

Going backward, the two-stage game has the following decision structure:

In stage 2 , the spouses simultaneously solve the following maximization problem:

$$
\begin{gathered}
\max _{c^{j}, q_{A}^{j}, q_{B}^{j}} \log \left(c^{j}\right)+\log \left(Q_{A}\right)+\log \left(Q_{B}\right), \text { for } j=H, W \\
\text { subject to } c^{j}+q_{A}^{j}+q_{B}^{j} \leq R^{J} .
\end{gathered}
$$

The first-order conditions for this maximization problem for both spouses give the following set of equations:

$$
\begin{gathered}
q_{A}^{H}+q_{A}^{W} \geq R^{H}-q_{A}^{H}-q_{B}^{H}, \\
q_{B}^{H}+q_{B}^{W} \geq R^{H}-q_{A}^{H}-q_{B}^{H}, \\
q_{A}^{H}+q_{A}^{W} \geq \alpha\left(R^{W}-q_{A}^{W}-q_{B}^{W}\right), \\
q_{B}^{H}+q_{B}^{W} \geq R^{W}-q_{A}^{W}-q_{B}^{W} .
\end{gathered}
$$

For each spouse to contribute to both public goods, all four equations should be satisfied with equality. However, as $\alpha>0$, it is immediately clear that this is impossible. The spouses contribute together at most to one public good, either A or B. Also, in equilibrium, the wife always contributes more to good A than B, and the contrary is true for the husband. We now study the different regimes of contribution to public goods. Let $S=R^{H} /\left(R^{H}+R^{W}\right)$ be the husband's income share. Table A1 presents all cases. We define four thresholds: $S_{1}=R^{H} / 3, S_{2}=2 /(3+\alpha), S_{3}=2 \alpha /(1+3 \alpha)$, and $S_{4}=3 \alpha /(1+3 \alpha)$. As the husband's income share decreases from $S_{4}$, the wife starts contributing to $Q_{A}$ until the household reaches the separate-sphere regime where each spouse specializes in the production of one public good (when $S_{2}<S<S_{3}$ ). As $S$ decreases further, the wife starts contributing to both goods until the husbands stops contributing altogether (when $S<S 1$ ).

Then, in the first stage, the husband determines the optimal level of transfers, $t$, taking as given the intra-household equilibrium of the second stage. Thus, he solves the following problem:

$$
\max _{t} V^{H}(t)
$$

$$
\text { subject to } t \leq B \text {. }
$$

where $V^{H}(t)$ is the indirect utility of the husband.

In this case, the indirect utility of the husband varies depending on the relative income. The equilibirum relative interval income in which the households ends up in changes with equilibrium transfers. We focus here on the cases in which the husband is richer, his initial income share being greater than $1 / 2$.

The husband's indirect utility in the second stage is

$$
\begin{array}{ccc}
V^{H}(t)=3 \log \left(\frac{Y^{H}+B-t}{3}\right) & \text { for } & S(B)>S_{4} \\
V^{H}(t)=3 \log \left(\frac{\alpha}{1+3 \alpha}\left(Y^{H}+B-t+Y^{W}+k t\right)\right) & \text { for } & S_{3}<S(B)<S(0) \leq S_{4} \\
V^{H}(t)=2 \log \left(\frac{Y^{H}+B-t}{2}\right)+\log \left(\frac{\alpha Y^{W}+k t}{1+\alpha}\right) & \text { for } & S(0) \leq S_{3}
\end{array}
$$

with $S(B)=Y^{H} /\left(Y^{H}+Y^{W}+k B\right)$ the husband's income share when he transfers the total assets $B$ to his wife, and $S(0)=\left(Y^{H}+B\right) /\left(Y^{H}+Y^{W}+B\right)$ his income share when he keeps all the assets.

For $S(B)>S_{4}$, it follows immediately that $t^{*}=0$. For $S(0)<S_{4}$, when both spouses are contributing to the same public good, $t^{*}=B$. Instead, for $S(B)<S_{4}<S(0)$, we have that 
either $t^{*}=B$ or $t^{*}=B$ depending on the level of $k$.

In particular, the condition for $t^{*}=B\left(t^{*}=0\right)$ is $k \geq \frac{1+3 \alpha}{3 \alpha}(<)$.

Finally, when $S(0)<S_{3}$, the husband solves the following maximization problem:

$$
\begin{gathered}
\max _{t} 2 \log \left(\frac{Y^{H}+B-t}{2}\right)+\log \left(\frac{\alpha Y^{W}+\alpha k t}{1+\alpha}\right) \\
\text { subject to } t \leq B .
\end{gathered}
$$

The optimal level of transfers in this case is

$$
t^{*}=\frac{Y^{H}+B}{2}-\frac{2 Y^{W}}{3 k} .
$$

Also, when $S(B) \leq S_{3}<S(0)$, we can identify the level of transfers that induces a regime change from joint contribution to specialization: $\bar{t}=\left[(1+\alpha)\left(Y^{H}+B\right)-2 \alpha Y^{W}\right] /[2 \alpha k+1+\alpha]$. Since it can easily be shown that $t^{*}=\left[\left(Y^{H}+B\right) / 2\right]-\left[2 Y^{W} /(3 k)\right]$ is always greater than $\bar{t}$, it follows that this is the optimal level in this case. 
Table A1: Public good contribution regimes.

Husband's income share $S$ Cases of contribution Equilibrium levels of public goods $\mathrm{H}=$ Husband, $\mathrm{W}=\mathrm{Wife}$

\begin{tabular}{llc}
\hline \hline$S>S_{4}$ & H: both goods & $q_{A}^{H}=q_{B}^{H}=\frac{1}{3} R^{H}$ \\
& W: none & \\
\hline$S_{3}<S<S_{4}$ & H: both goods & $q_{A}^{H}=\frac{1+\alpha}{1+3 \alpha} R^{H}-\frac{2 \alpha}{1+3 \alpha} R^{W}$ \\
& $q_{B}^{H}=\frac{\alpha}{1+3 \alpha} R^{W}+\frac{\alpha}{1+3 \alpha} R^{H}$ \\
W: $\operatorname{good} \mathrm{A}$ & $q_{A}^{W}=\frac{3 \alpha}{1+3 \alpha} R^{W}-\frac{1}{1+3 \alpha} R^{H}$
\end{tabular}

$S_{2}<S<S_{3}$

H: $\operatorname{good} B$

$q_{B}^{H}=\frac{1}{2} R^{H}$

W: $\operatorname{good} \mathrm{A}$

$q_{A}^{W}=\frac{\alpha}{1+\alpha} R^{W}$

(Separate Spheres)

$S_{1}<S<S_{3}$

H: good B

$q_{B}^{H}=\frac{1+2 \alpha}{1+3 \alpha} R^{H}-\frac{1+2 \alpha}{3(1+3 \alpha)} R^{W}$

W: both goods

$$
\begin{gathered}
q_{A}^{W}=\frac{\alpha}{1+3 \alpha} R^{W}+\frac{\alpha}{1+3 \alpha} R^{H} \\
q_{B}^{W}=\frac{2(1+\alpha)}{3(1+3 \alpha)} R^{W}-\frac{1+\alpha}{1+3 \alpha} R^{H}
\end{gathered}
$$

$S<S_{1}$

H: none

$q_{A}^{W}=\frac{\alpha}{2+\alpha} R^{W}$

W: both goods

$$
q_{B}^{W}=\frac{1}{2+\alpha} R^{W}
$$

Notes: $S_{1}=R^{H} / 3, S_{2}=3(1+\alpha) /(5+7 \alpha), S_{3}=2 \alpha /(1+3 \alpha)$, and $S_{4}=3 \alpha /(1+3 \alpha)$. 
Proof. Proposition 2 Going backward, the PBNE of three-stage game is as determined as follows: first, we derive optimal public good contributions given the information structure; then we find optimal transfers, given the information structure; then, we solve the communication equilibrium.

In stage 3 , conditional on the available information, spouses simultaneously solve the following maximization problems:

$$
\begin{gathered}
\max _{q_{A}^{W}(m), q_{B}^{W}(m)} \log \left(Y^{W}+k t(m)-q_{A}^{W}(m)-q_{B}^{W}(m) \mid k\right)+\alpha \log \left(Q_{A}(m) \mid k\right)+\log \left(Q_{B}(m) \mid k\right) \\
\max _{q_{A}^{H}(m), q_{B}^{H}(m)} \log \left(Y^{H}+B-t(m)-q_{A}^{H}(m)-q_{B}^{H}(m) \mid m\right)+E\left(\log \left(Q_{A}(m)\right) \mid m\right)+E\left(\log \left(Q_{B}(m)\right) \mid m\right)
\end{gathered}
$$

In stage 2, the husband solves:

$$
\max _{t} E\left[V^{H}(t) \mid m\right]
$$

In stage 1, the wife solves:

$$
\max _{m} V^{W}(m)
$$

In stage 1, the husband decides his contribution to the household public goods based on the expected behavior of the wife, given the wife's observed income and the productivity inferred through the message she sent in stage 1; the wife, however, is perfectly informed. Again, in stage 2 , the husband decides how much to assign to the wife, based on the message she sent in stage 1. Finally, when deciding which message to send the wife takes into account how it is going to affect the husband's behavior in stages 2 and 3 .

The BNE of the public good contribution, in stage 3, exists for every $p^{*}(k \mid m)$ (the husband posterior of the distribution of productivity given the message) resulting from the

communication game and every $t^{*}(k \mid m)$ resulting from the transfer equilibrium as the Kakutani Fixed Point applies.

In stage 3, the first-order conditions of the maximization problem of the wife are the same as the complete information problem. Given the public good contributions, the first-order condition for good $\mathrm{A}$ of the husband becomes:

$$
\frac{1}{Y^{H}+B-t-q_{A}^{H}-q_{B}^{H}}=\int_{\underline{k}}^{\bar{k}} \frac{1}{q_{A}^{H}+q_{A}^{W}(x)} F(x) d x .
$$

As before, we study how the husband's contribution varies with (expected) relative income. We make one simplifying assumption: the $\underline{k}-\bar{k}$ interval (the biggest interval on which, after communication, the productivity can be distributed, i.e. the interval corresponding to no information updating) is such that the distribution of expected relative income when all the resources are given to the wife is smaller than the smallest contribution interval (either $S_{2}-S_{3}$ or $S_{3}-S_{4}$ or $\left.S_{4}-1\right)$. We also denote $E(k)=k^{\prime}$.

When the relative income of the husband is very high, $q_{A}^{W}(k)=0$ for every $\mathrm{k}$. Then, we want to identify the level of (actual) relative income at which the wife starts contributing to good A. We know that this level is exactly equal to $S_{4}$ when the husband is completely informed. Now assume we are in the joint-contribution relative-income interval and the husband has rational expectations about the productivity of the wife. We can define $k^{4}: \lim _{k \rightarrow k^{4}} q_{A}^{W}(k) \rightarrow 0$. The first-order condition of the husband becomes:

$$
\frac{1}{Y^{H}+B-t-q_{A}^{H}-q_{B}^{H}}=\int_{\underline{k}}^{k^{4}} \frac{1}{q_{A}^{H}} F(x) d x+\int_{k^{4}}^{\bar{k}} \frac{1}{q_{A}^{H}+q_{A}^{W}(x)} F(x) d x .
$$

Since $\int_{k^{4}}^{\bar{k}} \frac{1}{q_{A}^{H}+q_{A}^{W}(x)} F(x) d x<\int_{k^{4}}^{\bar{k}} \frac{1}{q_{A}^{H}} F(x) d x$, it follows that in $S_{4}$, with incomplete information 
(II), $q_{A}^{* * H}<q_{A}^{* H}$. So the level of relative income at which $q_{A}^{W}$ starts to be 0 is lower than $S_{4}$. Symmetrically, we want to see what happens on the other edge of the interval, when the (actual) relative income is equal to $S_{3}$. Here, we compare the marginal return on consumption and public goods when $q_{A}^{H}=0$ (the optimal value in $S_{3}$ with complete information). Since we know that $u^{\prime}($.$) is convex in q_{A}^{H}$ it follows that:

$$
\frac{1}{Y^{H}+B-t-q_{B}^{H}}>\int_{\underline{k}}^{\bar{k}} \frac{1}{q_{A}^{W}(x)} F(x) d x .
$$

Thus in $S_{3}$, with II, $q_{A}^{* * H}>0$. So the level at which $q_{A}^{H}$ starts to be 0 is lower than $S_{3}$. The two thresholds are thus pushed towards the left.

We now analyze Stage 2 and derive the level of optimal transfers:

- when $\left[\frac{R^{H}}{R^{H}+R^{W}(\underline{k} B)}-\frac{R^{H}}{R^{H}+R^{W}(\bar{k} B)}\right] \in\left[S_{4}-1\right] \rightarrow t^{* *}=0$;

- when $\left[\frac{R^{H}}{R^{H}+R^{W}(\underline{k} B)}-\frac{R^{H}}{R^{H}+R^{W}(\bar{k} B)}\right] \in\left[S_{3}-S_{4}\right] \rightarrow t^{* *}=B$;

- when $\frac{R^{H}}{R^{H}+R^{W}(0)}<S_{3}$ then $t^{* *}=0$;

- it is easy to show that $t^{* *}=B$ as long as $q_{A}^{* * H}>0$ even when $S_{3} \in\left[\frac{R^{H}}{R^{H}+R^{W}(\underline{k} B)}-\frac{R^{H}}{R^{H}+R^{W}(\bar{k} B)}\right]$

- when $S_{3} \in\left[\frac{R^{H}}{R^{H}+R^{W}(\underline{k} B)}-\frac{R^{H}}{R^{H}+R^{W}(\bar{k} B)}\right]$ and $q_{A}^{* * H}=0$ we have $t^{* *}<t^{*}$ since the shape of the utility functioin imply that the Relative Risk Aversion of the husband is equale to 1. This in turns implies that the husband needs to reduce the transfer he sends to the wife, as compared to the complete information case, to equate the marginal utility from private consumption and from his preferred public good to the marginal utility of the public good provided by the wife that is now uncertian.

Finally, for all productivity levels, within a certain interval of relative income (perfectly observed by the wife), all types prefer to send the same message and no communication is possible in equilibrium (Crawford and Sobel, 1982). More formally: let's define as $m^{H}=\bar{k}$ as the message that the wife would send in equilibrium when the productivity realization is $k$. From the best reaction function of the husband with complete information, we know that $t^{*}(\bar{k})=t^{\text {max* }}$ that means that when the wife sends the message $m^{H}$ the husband will send the highest transfer. Since the Indirect Utility of the wife is growing in $t$, whatever the productivity realisation is, she will always declare $m^{H}=\bar{k}$. It follows immediately that $p(k \mid m)=F(k)$. 
Gender, information and the efficiency of household production decisions: An experiment in rural Togo

Online Appendix

September 17, 2019 


\section{A Experimental Design}

The following is a brief description of the experimental games, with a summary of the protocols (full version available in French and Ewe upon request).

Context and general instructions Each couple is invited to participate in 2 games. Game 1 ( $B T$ in the text) is the same for everyone. Subsequently 3 versions of Game 2 (ET, RT and $H T$ in the text) are randomly assigned. At registration, each couple receives an identification tag featuring the letter corresponding to their Game 2 assignment and their order of arrival.

Husbands and wives are placed in separate areas and assigned individual experimenters. To ensure confidentiality, experimenter-participant pairs are situated beyond hearing distance of each other. During the experiment, each experimenter reads the instructions aloud, explains them and tests the participant's understanding with questions. The game moves on only after each participant provides correct answers to all questions.

Participants are told they can each earn money during the games, the amount they receive being based both on the decisions made by the husband during the games and on the outcomes of two lotteries. These lotteries take place at the end of the games. The first lottery determines whether game 1 gains or game 2 gains will apply.The second lottery can increase or decrease the amount selected in the first lottery - there is even a chance of earning nothing. To place the second lottery in a realistic context, the experimenter refers to uncertainty in agricultural production related to unexpected events (weather, pests) that may act as positive or negative shocks and reminds participants how, when these events are extreme, farmers may lose everything.

Both husbands and wives know that their gains will be partly determined by the lotteries. Altough they know the basic structure of the lotteries, the wives are not invited to observe the lottery outcome. Payments are made in an individual and confidential way to each spouse. The husbands are informed that no one, including their wife, will know or can guess the decision they made and how much they will earn. The wives are informed that no one, except their husband, will know or can guess how much they will earn.

Game 1 (Base Treatment, same for all): Both men and women know the following:

- There are two separate plots of farmland. The woman is responsible for one of them, the man for the other.

- They have an endowment of 10 units of input to allocate between the two plots.

- Returns on each plot are constant, but they are twice as high on the female's plot as on the male's. In other words, yields increase linearly with the amount of input units used on each plot, but the increase is twice as high on the female's plot as on to the male's.

- They can talk freely for 5 minutes after they receive all instructions.

- The husband makes the allocation decision. He makes this decision privately after the couple's discussion.

- The husband is informed of potential gains from game 1 for himself and for his wife. Women neither observe nor are told about their husband's choice. They are not told how much they can earn from game 1.

- Both will take part in game 2.

\section{Game 2}


Experimenter Treatment (ET) Same as Base Treatment $(B T)$, the only difference being that now the returns from the female's plot are three times higher than from the male's. Participants are explicitly told that this is the only difference from the previous game. The experimenter reads the instructions and tests understanding. The men make a decision. As in $B T$, each man knows the potential gains he and his wife may make from game 2. As in $B T$, the women do not.

Hidden Treatment (HT) There are two differences from $B T$ that both members of the couple are informed of:

1. The experimenter tells the husbands that returns on their wife's plot are at least as large as in game 1 and that the returns on their own plot are unchanged.

2. The wife, rather than the experimenter, is now in charge of communicating the information on the returns from her plot.

As in $B T$, each man knows the potential gains he and his wife can make from game 2. As in $B T$, the wives do not, nor do they know the decision made by their husband.

Revealed Treatment (RT) There are three differences from $B T$ that both members of the couple are informed of:

1. The experimenter tells the husbands that returns on their wife's plot are at least as large as in game 1 and that the returns on their own plot are unchanged.

2. The wife, rather than the experimenter, is now in charge of communicating the information on the returns from her plot.

3. Both male and female participants know that the husbands will learn from the experimenters the returns on their wife's plot once they have made their allocation decision.

As in $B T$, each man knows the potential gains he and his wife can make from game 2. As in $B T$, the wives do not, nor do they know the decision made by their husband.

\section{B Theoretical Appendix}

\section{B.1 Cooperative decision-making}

\section{B.1.1 Optimal consumption allocations}

We define $\gamma$ as the pareto weight of the wife and $(1-\gamma)$ that of the husband. Thus, the household maximization problem is the following:

$$
\operatorname{Max} \gamma U_{i}^{W}+(1-\gamma) U_{i}^{H}
$$

which gives the optimal consumption levels:

$$
\begin{gathered}
Q_{A}^{*}=\frac{1+(\alpha-1) \gamma}{3+(\alpha-1) \gamma}\left(Y^{H}+Y^{W}\right) \\
Q_{B}^{*}=\frac{C^{* W}}{\gamma}=\frac{C^{* H}}{(1-\gamma)}=\frac{1}{3+(\alpha-1) \gamma}\left(Y^{H}+Y^{W}\right)
\end{gathered}
$$

\section{Optimal transfers}

In this case the indirect utility of the husband is:

$$
\begin{array}{r}
V^{H}(t)=\log \left(\frac{1+(\alpha-1) \gamma}{3+(\alpha-1) \gamma}\left(Y^{H}+B-t+Y^{W}+k t\right)\right)+ \\
(2-\gamma) \log \left(\frac{Y^{H}+B-t+Y^{W}+k t}{3+(\alpha-1) \gamma}\right)
\end{array}
$$


This is clearly maximized for $t^{*}=B$.

\section{B.2 Proofs}

\section{Proof. Proposition 1}

Going backward, the two-stage game has the following decision structure:

In stage 2 , the spouses simultaneously solve the following maximization problem:

$$
\begin{gathered}
\max _{c^{j}, q_{A}^{j}, q_{B}^{j}} \log \left(c^{j}\right)+\log \left(Q_{A}\right)+\log \left(Q_{B}\right), \text { for } j=H, W \\
\text { subject to } c^{j}+q_{A}^{j}+q_{B}^{j} \leq R^{J} .
\end{gathered}
$$

The first-order conditions for this maximization problem for both spouses give the following set of equations:

$$
\begin{gathered}
q_{A}^{H}+q_{A}^{W} \geq R^{H}-q_{A}^{H}-q_{B}^{H}, \\
q_{B}^{H}+q_{B}^{W} \geq R^{H}-q_{A}^{H}-q_{B}^{H}, \\
q_{A}^{H}+q_{A}^{W} \geq \alpha\left(R^{W}-q_{A}^{W}-q_{B}^{W}\right), \\
q_{B}^{H}+q_{B}^{W} \geq R^{W}-q_{A}^{W}-q_{B}^{W} .
\end{gathered}
$$

For each spouse to contribute to both public goods, all four equations should be satisfied with equality. However, as $\alpha>0$, it is immediately clear that this is impossible. The spouses contribute together at most to one public good, either A or B. Also, in equilibrium, the wife always contributes more to good A than B, and the contrary is true for the husband. We now study the different regimes of contribution to public goods. Let $S=R^{H} /\left(R^{H}+R^{W}\right)$ be the husband's income share. Table A1 presents all cases. We define four thresholds: $S_{1}=R^{H} / 3, S_{2}=2 /(3+\alpha), S_{3}=2 \alpha /(1+3 \alpha)$, and $S_{4}=3 \alpha /(1+3 \alpha)$. As the husband's income share decreases from $S_{4}$, the wife starts contributing to $Q_{A}$ until the household reaches the separate-sphere regime where each spouse specializes in the production of one public good (when $S_{2}<S<S_{3}$ ). As $S$ decreases further, the wife starts contributing to both goods until the husbands stops contributing altogether (when $S<S 1$ ).

Then, in the first stage, the husband determines the optimal level of transfers, $t$, taking as given the intra-household equilibrium of the second stage. Thus, he solves the following problem:

$$
\max _{t} V^{H}(t)
$$

$$
\text { subject to } t \leq B \text {. }
$$

where $V^{H}(t)$ is the indirect utility of the husband.

In this case, the indirect utility of the husband varies depending on the relative income. The equilibirum relative interval income in which the households ends up in changes with equilibrium transfers. We focus here on the cases in which the husband is richer, his initial income share being greater than $1 / 2$.

The husband's indirect utility in the second stage is

$$
\begin{array}{ccc}
V^{H}(t)=3 \log \left(\frac{Y^{H}+B-t}{3}\right) & \text { for } & S(B)>S_{4} \\
V^{H}(t)=3 \log \left(\frac{\alpha}{1+3 \alpha}\left(Y^{H}+B-t+Y^{W}+k t\right)\right) & \text { for } & S_{3}<S(B)<S(0) \leq S_{4} \\
V^{H}(t)=2 \log \left(\frac{Y^{H}+B-t}{2}\right)+\log \left(\frac{\alpha Y^{W}+k t}{1+\alpha}\right) & \text { for } & S(0) \leq S_{3}
\end{array}
$$

with $S(B)=Y^{H} /\left(Y^{H}+Y^{W}+k B\right)$ the husband's income share when he transfers the total assets $B$ to his wife, and $S(0)=\left(Y^{H}+B\right) /\left(Y^{H}+Y^{W}+B\right)$ his income share when he keeps all the assets.

For $S(B)>S_{4}$, it follows immediately that $t^{*}=0$. For $S(0)<S_{4}$, when both spouses are contributing to the same public good, $t^{*}=B$. Instead, for $S(B)<S_{4}<S(0)$, we have that 
either $t^{*}=B$ or $t^{*}=B$ depending on the level of $k$.

In particular, the condition for $t^{*}=B\left(t^{*}=0\right)$ is $k \geq \frac{1+3 \alpha}{3 \alpha}(<)$.

Finally, when $S(0)<S_{3}$, the husband solves the following maximization problem:

$$
\begin{gathered}
\max _{t} 2 \log \left(\frac{Y^{H}+B-t}{2}\right)+\log \left(\frac{\alpha Y^{W}+\alpha k t}{1+\alpha}\right) \\
\text { subject to } t \leq B .
\end{gathered}
$$

The optimal level of transfers in this case is

$$
t^{*}=\frac{Y^{H}+B}{2}-\frac{2 Y^{W}}{3 k} .
$$

Also, when $S(B) \leq S_{3}<S(0)$, we can identify the level of transfers that induces a regime change from joint contribution to specialization: $\bar{t}=\left[(1+\alpha)\left(Y^{H}+B\right)-2 \alpha Y^{W}\right] /[2 \alpha k+1+\alpha]$. Since it can easily be shown that $t^{*}=\left[\left(Y^{H}+B\right) / 2\right]-\left[2 Y^{W} /(3 k)\right]$ is always greater than $\bar{t}$, it follows that this is the optimal level in this case. 
Table A1: Public good contribution regimes.

Husband's income share $S$ Cases of contribution Equilibrium levels of public goods $\mathrm{H}=$ Husband, $\mathrm{W}=\mathrm{Wife}$

\begin{tabular}{llc}
\hline \hline$S>S_{4}$ & H: both goods & $q_{A}^{H}=q_{B}^{H}=\frac{1}{3} R^{H}$ \\
& W: none & \\
\hline$S_{3}<S<S_{4}$ & H: both goods & $q_{A}^{H}=\frac{1+\alpha}{1+3 \alpha} R^{H}-\frac{2 \alpha}{1+3 \alpha} R^{W}$ \\
& $q_{B}^{H}=\frac{\alpha}{1+3 \alpha} R^{W}+\frac{\alpha}{1+3 \alpha} R^{H}$ \\
W: $\operatorname{good} \mathrm{A}$ & $q_{A}^{W}=\frac{3 \alpha}{1+3 \alpha} R^{W}-\frac{1}{1+3 \alpha} R^{H}$
\end{tabular}

$S_{2}<S<S_{3}$

H: $\operatorname{good} B$

$q_{B}^{H}=\frac{1}{2} R^{H}$

W: $\operatorname{good} \mathrm{A}$

$q_{A}^{W}=\frac{\alpha}{1+\alpha} R^{W}$

(Separate Spheres)

$S_{1}<S<S_{3}$

H: good B

$q_{B}^{H}=\frac{1+2 \alpha}{1+3 \alpha} R^{H}-\frac{1+2 \alpha}{3(1+3 \alpha)} R^{W}$

W: both goods

$$
\begin{gathered}
q_{A}^{W}=\frac{\alpha}{1+3 \alpha} R^{W}+\frac{\alpha}{1+3 \alpha} R^{H} \\
q_{B}^{W}=\frac{2(1+\alpha)}{3(1+3 \alpha)} R^{W}-\frac{1+\alpha}{1+3 \alpha} R^{H}
\end{gathered}
$$

$S<S_{1}$

H: none

$q_{A}^{W}=\frac{\alpha}{2+\alpha} R^{W}$

W: both goods

$$
q_{B}^{W}=\frac{1}{2+\alpha} R^{W}
$$

Notes: $S_{1}=R^{H} / 3, S_{2}=3(1+\alpha) /(5+7 \alpha), S_{3}=2 \alpha /(1+3 \alpha)$, and $S_{4}=3 \alpha /(1+3 \alpha)$. 
Proof. Proposition 2 Going backward, the PBNE of three-stage game is as determined as follows: first, we derive optimal public good contributions given the information structure; then we find optimal transfers, given the information structure; then, we solve the communication equilibrium.

In stage 3 , conditional on the available information, spouses simultaneously solve the following maximization problems:

$$
\begin{gathered}
\max _{q_{A}^{W}(m), q_{B}^{W}(m)} \log \left(Y^{W}+k t(m)-q_{A}^{W}(m)-q_{B}^{W}(m) \mid k\right)+\alpha \log \left(Q_{A}(m) \mid k\right)+\log \left(Q_{B}(m) \mid k\right) \\
\max _{q_{A}^{H}(m), q_{B}^{H}(m)} \log \left(Y^{H}+B-t(m)-q_{A}^{H}(m)-q_{B}^{H}(m) \mid m\right)+E\left(\log \left(Q_{A}(m)\right) \mid m\right)+E\left(\log \left(Q_{B}(m)\right) \mid m\right)
\end{gathered}
$$

In stage 2, the husband solves:

$$
\max _{t} E\left[V^{H}(t) \mid m\right]
$$

In stage 1, the wife solves:

$$
\max _{m} V^{W}(m)
$$

In stage 1, the husband decides his contribution to the household public goods based on the expected behavior of the wife, given the wife's observed income and the productivity inferred through the message she sent in stage 1; the wife, however, is perfectly informed. Again, in stage 2 , the husband decides how much to assign to the wife, based on the message she sent in stage 1. Finally, when deciding which message to send the wife takes into account how it is going to affect the husband's behavior in stages 2 and 3 .

The BNE of the public good contribution, in stage 3, exists for every $p^{*}(k \mid m)$ (the husband posterior of the distribution of productivity given the message) resulting from the

communication game and every $t^{*}(k \mid m)$ resulting from the transfer equilibrium as the Kakutani Fixed Point applies.

In stage 3, the first-order conditions of the maximization problem of the wife are the same as the complete information problem. Given the public good contributions, the first-order condition for good $\mathrm{A}$ of the husband becomes:

$$
\frac{1}{Y^{H}+B-t-q_{A}^{H}-q_{B}^{H}}=\int_{\underline{k}}^{\bar{k}} \frac{1}{q_{A}^{H}+q_{A}^{W}(x)} F(x) d x .
$$

As before, we study how the husband's contribution varies with (expected) relative income. We make one simplifying assumption: the $\underline{k}-\bar{k}$ interval (the biggest interval on which, after communication, the productivity can be distributed, i.e. the interval corresponding to no information updating) is such that the distribution of expected relative income when all the resources are given to the wife is smaller than the smallest contribution interval (either $S_{2}-S_{3}$ or $S_{3}-S_{4}$ or $\left.S_{4}-1\right)$. We also denote $E(k)=k^{\prime}$.

When the relative income of the husband is very high, $q_{A}^{W}(k)=0$ for every $\mathrm{k}$. Then, we want to identify the level of (actual) relative income at which the wife starts contributing to good A. We know that this level is exactly equal to $S_{4}$ when the husband is completely informed. Now assume we are in the joint-contribution relative-income interval and the husband has rational expectations about the productivity of the wife. We can define $k^{4}: \lim _{k \rightarrow k^{4}} q_{A}^{W}(k) \rightarrow 0$. The first-order condition of the husband becomes:

$$
\frac{1}{Y^{H}+B-t-q_{A}^{H}-q_{B}^{H}}=\int_{\underline{k}}^{k^{4}} \frac{1}{q_{A}^{H}} F(x) d x+\int_{k^{4}}^{\bar{k}} \frac{1}{q_{A}^{H}+q_{A}^{W}(x)} F(x) d x .
$$

Since $\int_{k^{4}}^{\bar{k}} \frac{1}{q_{A}^{H}+q_{A}^{W}(x)} F(x) d x<\int_{k^{4}}^{\bar{k}} \frac{1}{q_{A}^{H}} F(x) d x$, it follows that in $S_{4}$, with incomplete information 
(II), $q_{A}^{* * H}<q_{A}^{* H}$. So the level of relative income at which $q_{A}^{W}$ starts to be 0 is lower than $S_{4}$. Symmetrically, we want to see what happens on the other edge of the interval, when the (actual) relative income is equal to $S_{3}$. Here, we compare the marginal return on consumption and public goods when $q_{A}^{H}=0$ (the optimal value in $S_{3}$ with complete information). Since we know that $u^{\prime}($.$) is convex in q_{A}^{H}$ it follows that:

$$
\frac{1}{Y^{H}+B-t-q_{B}^{H}}>\int_{\underline{k}}^{\bar{k}} \frac{1}{q_{A}^{W}(x)} F(x) d x .
$$

Thus in $S_{3}$, with II, $q_{A}^{* * H}>0$. So the level at which $q_{A}^{H}$ starts to be 0 is lower than $S_{3}$. The two thresholds are thus pushed towards the left.

We now analyze Stage 2 and derive the level of optimal transfers:

- when $\left[\frac{R^{H}}{R^{H}+R^{W}(\underline{k} B)}-\frac{R^{H}}{R^{H}+R^{W}(\bar{k} B)}\right] \in\left[S_{4}-1\right] \rightarrow t^{* *}=0$;

- when $\left[\frac{R^{H}}{R^{H}+R^{W}(\underline{k} B)}-\frac{R^{H}}{R^{H}+R^{W}(\bar{k} B)}\right] \in\left[S_{3}-S_{4}\right] \rightarrow t^{* *}=B$;

- when $\frac{R^{H}}{R^{H}+R^{W}(0)}<S_{3}$ then $t^{* *}=0$;

- it is easy to show that $t^{* *}=B$ as long as $q_{A}^{* * H}>0$ even when $S_{3} \in\left[\frac{R^{H}}{R^{H}+R^{W}(\underline{k} B)}-\frac{R^{H}}{R^{H}+R^{W}(\bar{k} B)}\right]$

- when $S_{3} \in\left[\frac{R^{H}}{R^{H}+R^{W}(\underline{k} B)}-\frac{R^{H}}{R^{H}+R^{W}(\bar{k} B)}\right]$ and $q_{A}^{* * H}=0$ we have $t^{* *}<t^{*}$ since the shape of the utility functioin imply that the Relative Risk Aversion of the husband is equale to 1. This in turns implies that the husband needs to reduce the transfer he sends to the wife, as compared to the complete information case, to equate the marginal utility from private consumption and from his preferred public good to the marginal utility of the public good provided by the wife that is now uncertian.

Finally, for all productivity levels, within a certain interval of relative income (perfectly observed by the wife), all types prefer to send the same message and no communication is possible in equilibrium (Crawford and Sobel, 1982). More formally: let's define as $m^{H}=\bar{k}$ as the message that the wife would send in equilibrium when the productivity realization is $k$. From the best reaction function of the husband with complete information, we know that $t^{*}(\bar{k})=t^{\text {max* }}$ that means that when the wife sends the message $m^{H}$ the husband will send the highest transfer. Since the Indirect Utility of the wife is growing in $t$, whatever the productivity realisation is, she will always declare $m^{H}=\bar{k}$. It follows immediately that $p(k \mid m)=F(k)$. 